\title{
Engineered muscle tissues for disease modeling and drug screening applications
}

Mohammad Hossein Mohammadi ${ }^{\mathrm{a}, \mathrm{b} \dagger}$, Raquel Obregón ${ }^{\mathrm{c} \dagger}$, Samad Ahadian ${ }^{\mathrm{b} \dagger}$, Javier Ramón-Azcón $^{\mathrm{d}, *}$, Milica Radisic ${ }^{\mathrm{a}, \mathrm{b}, *}$

a Department of Chemical Engineering and Applied Chemistry, University of Toronto, Toronto, Ontario, Canada

b Institute of Biomaterials and Biomedical Engineering, University of Toronto, Toronto, Ontario, Canada

${ }^{\mathrm{c}}$ Graduate School of Environmental Studies, Tohoku University, Sendai, Japan

${ }^{\mathrm{d}}$ Biosensors for Bioengineering group, Institute for Bioengineering of Catalonia (IBEC),

Baldiri Reixac 15-21, 08028 Barcelona, Spain

*Corresponding authors: Nanobiotechnology for Diagnostics (Nb4D) Group, IQAC-CSIC, Jordi Girona 1826, Barcelona, Spain. Fax: +34-93400-6100 (J. Ramón-Azcón). Institute of Biomaterials and Biomedical Engineering, University of Toronto, Toronto, Ontario M5S 3G9, Canada. Tel.: +1-416-946-5295. Fax: +1416-978-4317 (M. Radisic). E-mail addresses: javier.ramon@iqac.csic.es (J. Ramón-Azcón) and m.radisic@utoronto.ca (M. Radisic).

${ }^{\dagger}$ These authors contributed equally to this work. 


\begin{abstract}
Animal models have been the main resources for drug discovery and prediction of drugs' pharmacokinetic responses in the body. However, noticeable drawbacks associated with animal models include high cost, low reproducibility, low physiological similarity to humans, and ethical problems. Engineered tissue models have recently emerged as an alternative or substitute for animal models in drug discovery and testing and disease modeling. In this review, we focus on skeletal muscle and cardiac muscle tissues by first describing their characterization and physiology. Major fabrication technologies (i.e., electrospinning, bioprinting, dielectrophoresis, textile technology, and microfluidics) to make functional muscle tissues are then described. Finally, currently used muscle tissue models in drug screening are reviewed and discussed.
\end{abstract}




\section{Introduction}

It is obvious that harmonized movement is one of the most significant and common features of humans, which occurs by utilizing their muscles. Muscle tissues are made up of cells with the ability to change their length through contractile process. Skeletal muscle and cardiac muscle are the most important groups of vertebrates' muscles. A muscle that sticks to a bone of the skeleton and is responsible for preserving position and moving the body is called skeletal muscle and a heart muscle is named cardiac muscle. Microscopic images of skeletal and cardiac muscle cells (striated muscle) revealed a series of repeating units called sarcomeres, whereas smooth muscle cells lack this characteristic $(1,2)$.

Cardiomyocytes (CMs), endothelial cells (ECs), and cardiac fibroblasts constitute the native myocardium (3). The synchronous contraction of heart occurs due to CMs, which take up almost $90 \%$ of the myocardium volume (4). Extracellular matrix (ECM) surrounds CMs and provides physical support and biochemical cues to the cells (5). In particular, mitochondria supply continuous adenosine triphosphate that is needed in maintaining the cardiac contraction. CMs are connected end to end by intercalated disk junctions to form cardiac muscle (Figure 1-A). Besides overall resemblance between skeletal and cardiac tissues, there are some differences between them. Human skeletal muscle exhibits higher degree of multi-nucleation and a cardiac muscle. Skeletal muscles contract in response to a specific stimulus conveyed via a neuro-muscular junction and can be controlled at any time, whereas cardiac muscle exhibits autonomous activity and spontaneous contractions in cell culture (1). A heart muscle has to contract over 100,000 times a day without any break and relaxation (based on ordinary 70 beats per minutes) (6). .

Skeletal muscles, constituting about 40 percent of our body's weight, are made up of long cylindrical cells containing many nuclei, which are skeletal muscle fibers. The length and diameter of fibers differ from a few millimeters to more than $10 \mathrm{~cm}$ and 5 to $10 \mu \mathrm{m}$, respectively. Despite their long length, only few fibers reach the length of muscle tissue.. By magnifying the muscle fiber we reach myofibrils, which are also called myotubes (filamentary bundles with the approximate diameter of $0.1 \mu \mathrm{m}$, Figure 1-B) (7). Myofibers are made of a large number of sarcomeres that connect end to end with each 
other. Sarcomeres, as essential contractile units in striated muscles are separated from adjacent ones using Z-line (a thin border line between sarcomeres). The contractile process of skeletal muscle does not occur without interaction between two fundamental proteins in sarcomeres (i.e., myosin and actin) (1). One way to characterize a mature skeletal muscle is the analysis of sarcomere structure and contraction ability of muscles (8).

Cell survival, motility, and communication take place inside the ECM, which fills spaces among cells with specific biomolecules. In addition to provide mechanical structure for cells, the ECM is a suitable milieu for cell-cell and cell-matrix interactions, migration, differentiation, elongation, and proliferation of cells (9). The ECM for skeletal muscle is mainly composed of collagen type I with minor quantities of collagen types III, IV and $\mathrm{V}$, elastin, fibronectin, and laminin (10). In the other hand, the ECM for cardiac muscle mostly contains collagen types I and III, elastin, and glycosaminoglycans (11).

In what follows, we first describe the most important fabrication methods to make functional muscle tissue constructs. Current applications of engineered muscle tissues in disease modeling and drug screening are then reviewed and discussed.

\section{Engineering muscle tissues}

Cardiovascular diseases (CVDs) (e.g., myocardial infarction (12)) are among the most life-threatening disorders world-wide. According to the American Heart Association, CVDs are the leading cause of death internationally (13). It is anticipated that by 2030, 23.6 million people will die because of CVDs, such as heart failure, arrhythmia, and heart valve problems. CVD-related parameters may affect cholesterol, fat, and insulin levels in the body (14). In addition, loss of skeletal muscle functionality is inevitable due to muscle diseases, aging, and injuries. Due to the paucity of allograft muscle tissues for transplantation, muscle tissue engineering as a promising strategy has drawn attention to provide alternative methods to overcome muscle diseases and injuries. 
Tissue engineering, with the ultimate goal of developing functional tissues, aims to recover or replace damaged or diseased tissues and organs (2). As a critical point in tissue engineering, designing and fabricating a suitable microenvironment for cells that resembles the natural ECM is playing an important role. Scaffolds as the biomimetic ECM should have structural, mechanical, and biological properties close to those in the ECM. In addition, they need to be biocompatible and biodegradable. It is considered that reproducing physico-chemical properties of each specific native tissue environment provides ideal design criteria for tissue engineering scaffolds (15). Microfabrication techniques have been utilized in fabricating functional tissue constructs during the past decades. Here, we highlight commonly used technologies (i.e., electrospinning, bioprinting, dielectrophoresis (DEP), textile approaches, and microfluidics) in manipulating muscle cells and making functional muscle tissues.

\subsection{Electrospinning}

The history of electrospinning technique goes back to the 1930s when Formhals synthesized fibers utilizing electric charges (16). While this technique did not gain scientific attention for many years, it has recently found widespread applications in tissue engineering (17), drug delivery (18), textile (19), filtration (20), catalysis (21), nanofiber

reinforcement (22), and wound healing (23). Besides scientific applications, the electrospinning technique has various industrial applications as reviewed elsewhere (24). Electrospinning is a simple, low-cost, and adaptable approach for synthesizing polymeric fibers from a polymer melt or solution using an electric field. The size of fibers (ranging from a few nanometers (nanofibers) to microns) can be controlled by some factors, such as solution feed rate, applied voltage, and viscosity of polymeric solution (Figure 2-A) $(2,25,26)$. The main reason to utilize the electrospinning technique for tissue engineering applications is morphological resemblance between electrospun fibers as the scaffold and natural ECM, such as Type I collagen (2, 27). Besides cell attachment and proliferation, desirable oxygen and nutrient transport properties can also be achieved as a result of high surface area/volume ratio and microporosity of electrospun fibers $(28,29)$. By choosing appropriate material or composite for electrospun fibers, it is possible to tune proper geometries and properties of fiber scaffolds (30). 
Precise control of fiber alignment is a key parameter for application of electrospun fibers in muscle tissue engineering. Scaffolds with anisotropic or unidirectional orientation guide morphogenesis of muscle cells and boost cell functionality compared to randomly oriented fibers. Choi et al. used a mixture of polycaprolactone (PCL) and collagen as electrospun nanofiber scaffolds and seeded human skeletal muscle cells on them. Their results showed myotube length on the unidirectional oriented scaffolds was more than twice of that observed on randomly aligned ones, whereas no noticeable differences were reported between myotube diameters (31). In another study, poly(lactic-co-glycolic acid) was employed to fabricate highly aligned electrospun fibers with a diameter ranging from $100-\mathrm{nm}$ to $1.4-\mu \mathrm{m}$. The synthesized scaffolds without any surface modification provided appropriate conditions for cell attachment, alignment, differentiation, and proliferation of C2C12 murine myoblasts (26).

Applying electrical stimulation to electrospun fibers (for example PCL or polyurethane (PU) fibers) can improve tissue formation and functionality. Adding multiwalled carbon nanotubes (CNTs) in electrospun fibers also induced muscle cell differentiation and increased electrical conductivity of fibers (32). Electrospun CNT-PU scaffolds enhanced differentiation of myoblasts to myotubes under electrical stimulation compared with the same scaffolds without stimulation (15). Liao et al. studied the effect of electrical stimulation on muscle cells cultured on aligned PU electrospun fibers. Their results showed an increase from $70 \%$ to $85 \%$ of striated myotubes after applying electrical stimulation on day 7 of culture. Higher cellular elongation and alignment and more striated myotubes were also observed on aligned fibers compared with random fibers (8).

Besides widespread applications of the electrospinning technique, there are few practical limitations (2). For example, as fiber diameter decreases to the nanoscale, the average pore size of the scaffold and consequently cellular infiltration into the fibers decreases. This results in non-uniform dispersion and migration of cells onto the electrospun nanofibers that restrict vascularization and tissue formation (33). Moreover, a potential source of cytotoxicity are chemical residues from electrospun fibers. It is suggested to utilize water as a solvent in order to prevent such toxicity (34). Insufficient mechanical strength is a challenge for some electrospun scaffolds, which is necessary for load bearing 
applications and appropriate biodegradation of fibers (35). Finally, slow rate of production is an issue that discourages people from using the electrospinning technique (36).

\subsection{Bioprinting}

In 1986 Charles W. Hull called his three-dimensional (3D) printing method "stereolithography" for the first time. He utilized ultraviolet light to cure consecutively printed thin layers of material to make a 3D construct (37). This technology is able to rapidly fabricate micro- and macroarchitectures without compromising the cellular viability (38). A 3D tissue construct can be formed from precise placement of biomaterials and living cells sequentially using the 3D printing approach. The main bioprinting methods include inkjet bioprinting (39-41), laser-assisted bioprinting (LAB) (42-44), and extrusion-based bioprinting (EBB) (45-47). Inkjet bioprinting method is the most prevalent one, which utilizes thermal (39) or acoustic (48) forces to expel desirable amounts of materials on the anticipated location. However, liquids can only exit from inkjet bioprinters and need further treatment to form solids. LAB is based on laserinduced forward transfer in which metals, peptides, DNA, and cells can be printed (43). Unlike other methods, LAB is nozzle-free and enables printing of materials with a wide range of viscosity and cells with high cell viability and functionality. Despite its advantages, slow flow rate and high setup cost are the major concerns associated with using this technique (49). EBB is appreciated for its notable deposition and printing speed, affordable and commercialized hardware, and ability to print a wide range of bioinks, such as cell encapsulated hydrogels (50), microcarriers (51), and cell aggregates (52). Compared to the aforementioned methods, limited resolution, solidification process, and low cell viability due to shear stress of the nozzle are major disadvantages of EBB (53).

Bioprinting is an outstanding technique to spatially pattern and distribute cells and ligands inside scaffolds. Kang et al. recently introduced an integrated tissue-organ printer for creation of tissue structures (Figure 2-B). They printed mouse myoblasts to form 3D muscle structures $(15 \mathrm{~mm} \times 5 \mathrm{~mm} \times 1 \mathrm{~mm})$. At day 3 of culture, linear stretching and compaction of viable cells were observed and the formation of muscle-like constructs having aligned myotubes was reported at day 7 of culture. After 2 weeks of implantation, 
nerve integration and vascularization were revealed by the expression of specific markers (54). In another study, differentiation of C2C12 muscle cells incorporating chemical and geometric cues was investigated. An inkjet bioprinter was utilized in printing bone morphogenetic protein-2 and fibroblast growth factor-2 to induce the differentiation of mouse C2C12 myoblasts into tenocytes and osteoblasts, while in the absence of growth factors myotubes were formed (55).

\subsection{Dielectrophoresis}

DEP is an electrokinetic technique applied for cellular characterization (56), particle separation $(57,58)$ and manipulation (59-61), and fabrication of biomimetic scaffolds (62, 63). This technique was first introduced by Herbert Pohl in the 1950s (64). DEP is defined as the motion of dielectric particles within a medium due to an exposed inhomogeneous electric field $(65,66)$. Migration of particles occurs as a result of an electric field gradient in medium. An AC field is usually used to induce the polarization of particles and medium. The DEP force is influenced by particles' dielectric behavior and size, frequency of electric field and electrical characteristics of medium (67). If the particle is more polarizable compared to the occupying medium, the particle is driven to areas with large electric fields. This occurrence is noted as positive DEP. On the other hand, negative DEP refers to the case where the particle is less polarizable in comparison to the medium. This leads to migration of particles from regions of high electric field (68).

DEP was employed for aligning nanoparticles in scaffolds for tuning their characteristics for tissue regeneration and cell therapy applications (69). For example, we successfully fabricated functional skeletal muscle tissues using dielectrophoretically aligned CNThydrogel scaffolds (70). The CNTs were aligned in gelatin methacrylate (GelMA) hydrogel via DEP for controlling electrical and mechanical properties of scaffolds (Figure 2-C). The Young's modulus of the resulted hydrogel was $23.4 \pm 0.2 \mathrm{kPa}$ (close to the elasticity of the native muscle tissue). In addition, the hydrogel showed anisotropic electrical conductivity for fabrication of aligned and contractile muscle myofibers (71). Different factors, such as voltage, frequency, and ionic conductivity of medium can influence properties of dielectrophoretically manipulated scaffolds (72). Dunne et al. explored effects of some parameters on properties of silk nanofibrous scaffolds prepared 
by the DEP technique. They reported that decrease in the fibril size can be achieved by increasing the DEP frequency (62). However, there are some limitations and disadvantages associated with the DEP approach. For example, dynamic particles have altering dielectric characteristics based on their size and shape. Therefore, particles of the same type may have different dielectric properties in DEP devices (66). In addition, DEP needs precise sample handling in small amounts, which limits its application in large scale (73).

\subsection{Textile technology}

Textile technologies, originally developed for manufacturing clothes and ornamental fabrics, have newly become a promising approach for fabrication of fibrous scaffolds in tissue engineering (74-76). The variety of textile manipulation approaches (e.g., weaving (Figure 2-D) (77, 78), knitting $(79,80)$, and braiding $(81,82)$ provide accurate control over pore size, surface topography, and pore interconnectivity of fibers and cellular distribution within them (83). Constituent units of textile fibers in tissue engineering can be natural $(84)$, synthetic $(85,86)$, and composite $(87,88)$ fibers. The Acorn CorCap ${ }^{\mathrm{TM}}$ cardiac support device is an example of a textile based device used in the cardiac field (89). In addition to mechanical property, each device or graft provides cellular attachment, proliferation, and alignment. Therefore, textile-based grafts and devices can be specified for different tissues or organs (77).

Some research groups have utilized textile techniques in cardiac tissue engineering (90). This fabrication method can provide suitable mechanical properties and cellular alignment for CMs. As an outstanding example, knitted mesh of neonatal rat heart cells and fibrin formed a hybrid cardiac construct (91). Hyaluronan benzyl ester was selected as a knit, since hyaluronan is available in the native cardiac tissue. The presence of knit enhanced the mechanical properties of constructs, which experienced cyclic mechanical load in the experiment. This hybrid cardiac construct revealed higher modulus and tensile strength than the native myocardium. Other fabrication methods can be incorporated with textiles to achieve desirable characteristics of scaffolds. Şenel-Ayaz et al. utilized both electrospinning and textile technology to create textile-template electrospun fibers 
showing various 3D micropatterns based on the type of fabric used as a template (83). In addition, heart valve engineering has also been performed based on textile and electrospinning methods $(92,93)$. By incorporating micromolding technique with textile technology, Hosseini et al. introduced a simple approach, called fiber assisted molding (FAM) for making curved micropatterns (94). They utilized FAM to fabricate 3D helical structures to achieve highly aligned myoblasts and myotubes.

\subsection{Microfluidics}

Microfluidics is a technology that is generally defined by perfusion of fluids in channels with miniaturized diameters ranging from tens to hundreds of micrometers (95). Microfluidic systems reduce sample volume compared to macroscale counterparts and thereby decrease reagent cost (96). Microfluidic techniques gain advantages from specific features of the microscale world, such as laminar flow that prevents fluid mixing in the microchannels (97). Besides surface tension, capillary force is a predominant factor that should be considered in the design of microfluidic platforms (98). Microfluidics is an interdisciplinary field that has a wide range of applications in biomedical engineering, chemical biosensors, cell analysis, and diagnostics (99). For instance, lab-on-a-chip concept that has attracted worldwide attention in the last decade is mainly relies on microfluidics (100).

In addition to heart-on-chip platforms, microfluidic technology is utilized for many biomedical applications including bio-actuators (101), contraction analysis of cells (102), and dynamic cell culture models (103). Shimizu et al. fabricated a microfluidic device to achieve 3D contractile skeletal muscle tissues. They used C2C12 cells embedded inside collagen and made gels inside microchannels. The muscle contraction was observed under different electrical stimulation conditions (twitch $(1 \mathrm{~Hz})$ and tetanus $(50 \mathrm{~Hz})$ ).

In addition to disease modeling and drug screening, engineered muscle tissues may have other applications in regenerative medicine (104), bio-actuators or bio-robots (105), biological electrochemical systems (gaining electricity and other source of energy from muscle contraction) (106), and food industry (107). These important applications are not the scope of this review. Therefore, in the next section, we focus on the applications of engineered muscle tissues in disease modeling and drug screening. 


\section{Applications of engineered muscle tissues in drug screening}

Most studies for drug development use animals to model pharmacological response of the human body. Physiological and metabolic differences between animals and humans make it difficult to precisely model the effect of drugs. Recent advances in biomaterial development, tissue engineering, and microscale technologies have helped to develop functional organs-on-a-chip platforms for different drug screening and diagnostics applications. However, despite significant advances in the field of tissue engineering, little work has been done towards using 3D engineered tissues as functional tools in pharmacological research and development. Likewise, little investigations have been devoted to using 3D muscle tissues in pharmacological applications.

In vitro studies should mimic the natural response of human tissues in laboratory. To achieve this goal, a culture system should be constructed according to the physiology of healthy or diseased tissue or organ. Generally, several microenvironment cues should be provided for muscle cells to enhance their maturation and functionality in vitro (108). For example, growth factors and other supplements have been used as the biological cues to regulate muscle cell behavior (109). Insulin-like growth factor 1 (110) and transforming growth factor beta 1 (111) are among the most important growth factors that enhance the maturation and contractility of muscle cells. In addition, substrate properties play an important role in proliferation and differentiation of muscle cells by providing elastic substrates, similar to the native niche (112). 3D cell cultures barricade improper signaling and provide better cell-cell and cell-ECM communications compared to 2D platforms (113). Mechanical stretch regimes (passive tension or active forces) revealed potential capability to elevate the maturation and differentiation of different cell types especially muscle cells. For instance, Montevecchi et al. seeded C2C12 cells on electrospun membranes (114). Their results showed that by applying cyclic stretching (three successive movement with frequency of $0.5 \mathrm{~Hz}$, which induced 3.4\% deformation of substrate), myosin accumulation was increased eight times compared to non-stimulated cultures. Besides applying mechanical cues to enhance cell differentiation, alignment, and functionality (115), electrical stimulation can exercise muscle cells and persuade cells to obtain and improve their structural and functional ability (116). We electrically stimulated 
myotubes through interdigitated array of Pt electrodes deposited under the muscle tissue. Electrical stimulation of C2C12 myotubes (voltage and frequency were $6 \mathrm{~V}$ and $1 \mathrm{~Hz}$ ) increased the alignment and elongation of myotubes (Figure 3-A, B) (117).

There are other factors that need to be considered for mimicking the natural environment of muscle cells, such as cell alignment (118). In Figure 3-C, electrical and topographical cues are incorporated to achieve aligned myotubes (71). Moreover, co-culturing of muscle cells with appropriate surrounding cells provides an in vivo-like environment that enhances the cellular maturation. For instance, co-culturing skeletal muscle with motor neurons, endothelial cells or tenocytes has shown a significant impact on muscle tissue maturation (119). Recently, making neuromuscular junctions in engineered skeletal muscle tissues has gained an increasing attention $(120,121)$. Tissue development in vivo and in vitro are time dependent (122). In the other word, by passing more time muscle cells become more mature. Smith et al. showed that contractile force of myotubes had a noticeable increase from day 14 to day 21 in contrast to first two weeks of culture (123).

\subsection{Cardiac muscle}

Significant advances have been made in the field for cardiac regeneration (124-127). Some regeneration strategies focus on scaffold-free concepts, such as the generation of multi-layered cardiac cell sheets (128-131) and the generation of multicellular aggregates named spheroids $(132,133)$. On the other hand, scaffold-based approaches use both natural (134-140) and synthetic (141-144) biomaterials as the scaffold. Conventional twodimensional (2D) platforms for drug testing are static and do not mimic the complicated cell-matrix and cell-cell interactions in the native cardiac tissue $(145,146)$. The combination of tissue engineering with microfluidic technologies has expedited the development of heart-on-a-chip platforms that can be used as emerging tools for in vivolike applications of cardiac tissues (147-149). For example, Tanaka et al. developed a novel microspherical heart-like pump device powered by spontaneously contracting neonatal rat CM sheets (101). This system was fabricated by rolling a beating CM sheet onto a fabricated polydimethylsiloxane (PDMS) hollow elastomeric sphere fixed with 
inlet and outlet ports. Young et al. fabricated a 2-layer microfluidic device to study the permeability of EC monolayers on porous membranes under shear stress conditions (150). The PDMS device consisted of lower and upper microchannels and a porous membrane separated them. Later, the authors modified the microfluidic device to recapitulate 3D vascular system and studied the physiological cardiovascular cell-cell interactions (151). Li et al. fabricated a microfluidic chip integrated with an acoustic wave sensor to study the cardiac muscle cell contraction (152). The device has potential application to study contractile activity of a single heart muscle cell during drug screening.

Recent studies have been devoted to developing heart-on-a-chip platforms for pharmaceutical applications (153-158). Earlier studies used CMs derived from animals, as they were widely accessible. For example, Parker and colleagues developed muscular thin film (MTF)-based systems and employed them for pharmacological and contractility studies (159-161). They quantified the contractility of rat CMs as a result of epinephrine exposure (159). The CMs were micropatterned on thin poly(Nisopropylacrylamide)/PDMS elastomers (Figure 4-A). They assembled eight separate MTFs on a single device. With this novel system, the authors were able to quantify the contractility of several cardiac muscle tissues simultaneously (Figure 4-B). Two years later, Agarwal et al. modified the heart-on-a-chip system and used it to test isoproterenol on cardiac muscle contractility (160). The authors developed semiautomatic device incorporating a system to control drug injection, temperature, and electrical stimulation (Figure 4-C). The device consisted of a simple microfluidic channel, which is reusable, transparent, and biocompatible and did not require specialized skills to use it. The microdevice was tested with continuous perfusion of isoproterenol at different exposures during electrical stimulation of MTF. This new device is suitable for high-content drug testing in cardiac muscle tissues in vitro.

Eschenhagen and Zimmerman developed a cardiac model, called engineered heart tissue (EHT), employing embryonic chick CMs suspended in a collagen matrix (162). Some years after, the same research group reported improvements of their device and used neonatal rat CMs in a Matrigel/collagen gel (163). The authors prepared 3D circular EHTs by culturing CMs around a central Teflon cylinder. Compared to other techniques for engineering cardiac muscles, this system exhibited a higher cardiac tissue/matrix ratio, 
contractility, and maturation. Hansen et al. modified their device to obtain mini-EHTs in a fibrinogen/thrombin/Matrigel matrix (145). The authors used fibrinogen and thrombin instead of collagen because the polymerization of hydrogel was more rapid than the gelation of collagen. The authors used the ring format instead of a strip format in creating mini-EHTs. Posteriorly, the 24-well mini-EHTs format was used to evaluate 46 proarrhythmic drugs under perfusion and/or electrically stimulation on the contractile activity of muscle tissues (164). The study was carried out with 14 to 21-day old miniEHTs and three different concentrations of drugs. The authors observed that the miniEHTs were sensitive to the drug concentrations. Recently, Eschenhagen group utilized the EHTs to explore tyrosine kinase inhibitors-mediated cardiotoxicity using immunohistology and transmission electron microscopy (165).

Recently, Kaneko et al. developed a cell-based model using an agarose microchamber array chip to evaluate the effect of haloperidol on mouse CM beating activity (166). The authors developed two systems, a four-cell and a nine-cell CM network. They observed that the beating rhythm of the CMs were unstable and slower after the addition and wash out of haloperidol in the four-CM network because this system was not large enough to re-establish a stable beating state. Instead, the beating rhythm was returned to its original state after the haloperidol wash in the nine-cell network. These results showed the importance of tissue culture size on the stability of drug screening models. Song et al. reported a diabetic cardiac tissue to test the effect of antidiabetic thiazolidinedione drugs. For that purpose, the authors cultured rat CMs in collagen gels under different media conditions to reproduce a diabetic myocardium (167). The authors studied the CMs under normal, diabetic, and therapeutic conditions. Their results showed that CMs cultivated with high glucose media showed low current propagation and high cell apoptosis. Thiazolidinedione enhanced electrical properties and viability of CMs. The proposed platform is suitable for drug screening on engineered cardiac tissues in diabetic conditions.

Functional CMs can be obtained from human pluripotent stem cells (hPSCs), including induced pluripotent stem cells (iPSCs) and human embryonic stem cells (ESCs) (168173). Despite their immature characteristics, extensive pharmacological studies have shown that iPSC-derived CMs accelerate drug screening, enable more accurate prediction of human cardiac response to pharmacotherapy, and provide tools for personalized drug 
screening assays to timely and accurately predict a patient's drug response. Braam et al. used iPSC-derived CMs for toxicity assessment of different drugs (174). Most pharmaceutical companies have established iPSC research sections or closely collaborate with scientist groups to explore the potential of these cell populations in predictive pharmacology, toxicology, and personalized medicine. In another study, Nunes et al. created a platform called "biowire" to employ structural and electrical cues in order to mature hPSC-derived CMs. Seeded cells inside collagen were showed higher maturation by applying electrical stimulation. The stimulated biowires exhibited an enhancement in organization, conduction velocity, and $\mathrm{Ca}^{+2}$ handling (175).

Xiao et al. developed a perfusable bioreactor to generate 3D microtissues (a typical biowire) using both neonatal rat CMs and human ESC-derived CMs (176). The system was implemented with electrical stimulation (carbon rod electrodes) to improve the maturation of CMs. The authors tested cardiac biowires with nitric oxide and observed that the beating rate was decreased after the treatment. Serena et al. engineered a multilayered microfluidic platform for pharmacological analysis on human CMs (177). The device was fabricated using the conventional lithographic technique and molded in PDMS. They then exposed the human CMs to hydrogen peroxide $\left(\mathrm{H}_{2} \mathrm{O}_{2}\right)$ to mimic the oxidative stress implicated in various disease states and observed that contractile activity was dramatically suppressed.

Many recent studies focused on engineering cardiac tissue constructs from iPSC-derived CMs (178-180). Cardiac muscle tissues obtained from human iPSCs combined with microfluidic systems has become a useful platform to improve preclinical pharmacology as well as drug discovery approaches. Incorporating vasculature in engineered cardiac tissue is needed to enhance physiological fidelity and enhance tissue survival. George and colleges created perfused human capillary networks from human endothelial colony forming cell-derived ECs (Figure 5) (181). Later, the authors combined the network of human capillaries in the presence of cardiac muscle spheroids derived from human iPSCs to fabricate a vascularized cardiac microtissue (Figure 5-C) (182). Their results showed that human CMs survived and continued to contract within the device for up to 28 days, while a surrounding vessel network was developed. 
Mathur et al. developed a human cardiac microphysiological system from human iPSCderived CMs for pharmacological studies (183). The novel device contained a cell chamber, two neighboring channels for medium, and some connecting microchannels mimicking the endothelial barrier. This barrier protected the muscle tissue from shear forces and allowed the diffusion of nutrients. The authors obtained robust and reproducible human 3D aligned cardiac microtissues modifying a previous study in serum-free media (184). Human iPSC-derived CMs started beating spontaneously and without any external stimulation. After 7 days, multiple cell layers started to contract in a uniaxial manner. The engineered cardiac tissue was tested with four model drugs (verapamil, E-4031, isoproterenol, and metoprolol). The results showed a good correlation of tissue response to those previously recorded with other methods in human cardiac cells. For example, the addition of isoproterenol enhanced the tissue beating. All aforementioned investigations show a great progress in the development of reliable cardiac tissues in vitro for disease modeling and drug screening applications. Moreover, they emphasize that the cardiac tissue-on-chip models generally have better prediction of clinical results compared to conventional 2D culture models. Our lab recently developed a tissue construct named “AngioChip”, the most advanced vascularized cardiac platform to date, which combined multiple layers of branched networks (Figure 2-E). Microholes and nanopores within the tissue scaffold were prepared to fortify permeability and cell migration. Developed cardiac tissues with AngioChip technology were implanted in vivo and successfully connected with the vasculature system of the host (185).

\subsection{Skeletal muscle}

In general, skeletal muscle tissue engineering uses cells, scaffolds, and growth factors aiming to regenerate native skeletal muscles (186). Several cell types, such as satellite cells, myoblasts, mesoangioblasts, pericytes, embryonic stem cells, mesenchymal stem cells, and iPSCs have been identified as potential sources for cells for skeletal muscle regeneration $(117,187)$. In addition, different methods to construct 3D skeletal muscles in vitro have been developed with the ability to apply both mechanical and electrical stimulations (188). These techniques focus on scaffold-free concepts (189-191) or on scaffold-based approaches (192-195). Numerous groups have documented the use of 3D skeletal muscle tissues as in vitro models for pharmacological screening tests or 
biological studies (196-198). For example, Syverud et al. developed 3D skeletal muscle units (SMUs) and examined the potential of dexamethasone as a growth factor (199). SMUs were tissue constructs fabricated from contractile myotubes and monolayers of primary fibroblasts. The results showed that dexamethasone improved myogenic proliferation and myotube fusion when it was added before induction of differentiation. Moreover, SMUs exposed to $10 \mathrm{nM}$ of dexamethasone on day 6 or day 0 showed organized muscle structure and enhanced force production.

Tourovskaia et al. fabricated a microfluidic platform to stimulate myotubes with agrin, a chemical expressed by neurons in vivo at the nerve-muscle junction $(200,201)$. The microfluidic system was fabricated using soft lithography in PDMS and consisted of a main channel formed by different numbers of converging inlet channels for the delivery of drugs to the myotubes. The results suggested that agrin is an important stabilizer in the synapse formation. This microfluidic device allowed an accurate control of perfusion and chemical environment surrounding cells. In addition, the device can be used for studies of spatiotemporal competition between different stimuli. In another work, Anene-Nzelu et al. developed 3D microfluidic systems with microtopographical cues to obtain aligned myoblast constructs (202). The top layer of the system consisted of a microfluidic channel with a micropillar array to immobilize C2C12 cells and a bottom PDMS microgrooved layer. The authors observed that C2C12 cells aligned along the direction of microgrooves. In addition, it was observed that the alignment enhanced the maturation of myoblast constructs and the expression of skeletal muscle genes. The proposed microfluidic system is simple, cost-effective, and scalable and can be used as a powerful platform for drug screening.

Although several strategies have been proposed to make contractile 3D skeletal muscles in vitro, Vandenburgh et al. made the most significant contribution toward using engineered muscle tissues in drug screening. They developed miniature bioartificial muscles (mBAMs) in 96-well plates (203, 204). mBAMs were 3D contractile tissues with organized and striated skeletal muscle fibers, which can generate directed force when electrically stimulated. In their model, murine myoblasts were mixed with collagen, Matrigel, or fibrinogen-thrombin gels and cast in a flexible well with microposts on each side (Figure 6). This approach provided a nondestructive and sensitive method for 
measuring muscle contractile forces. Preliminary work tested Atorvastatin and insulinlike growth factor-1 on healthy murine muscle fibers (205). The results demonstrated mBAM myofiber active force and hypertrophy were enhanced as the muscle tissues were exposed to insulin-like growth factor-1. However, mBAM weakness and deterioration were reported for the tissues exposed to a cholesterol-lowering statin. Following this work, the system was automated and was used for high-throughput screening experiments (206). The author tested the effects of 31 potential dugs on mdx mouse-derived mBAMs to treat Duchenne muscular dystrophy. The results showed that 11 compounds enhanced the muscle force generation. The novel automated system can be used as a powerful preclinical tool in pharmaceutical applications.

Recently, Madden et al. fabricated human skeletal muscle culture systems, named myobundles, using primary myogenic cells to study their contractile activity and biochemical responses to three different drugs (207). Myogenic cells were derived from human muscle biopsy and human myobundles were generated using a hydrogel molding method previously described with rat cells (208). After 5 days of differentiation, the myofibers showed spontaneous contraction. Human myobundles were tested with statins (cerivastatin and lovastatin), chloroquine, and clenbuterol and their contractile and biochemical responses were recorded. The results showed that myobundles exhibited aligned architecture, multinucleated, and striated myofibers. Also, they contracted spontaneously and responded to electrical and biochemical stimuli. The authors observed that myobundles were more sensitive to cerivastatin than lovastatin, which agrees with previous clinical reports. In response to chloroquine, myobundles induced the autophagic myopathy observed in muscle tissues in vivo. Clenbuterol at low concentration caused the myofiber hypertrophy and increased contractile strength of myobundles. However, higher concentrations of clenbuterol led to muscle weakness consistent with previous animal and human studies. In general, these studies suggested that myobundles were able to recapitulate the physiological responses of native muscles and can be used as a preclinical tool for predictive pharmacological screening.

\section{Future work}


Recent advances in biomaterial synthesis, stem cell biology, and microfabrication technologies have enabled researchers to develop biomimetic and physiologically relevant muscle tissue constructs for drug screening and disease modeling applications. However, despite significant progress in generating muscle tissues for screening novel drugs, more sophisticated tissue models are needed to make reliable assessment of compound efficacy or toxicity. Development of advanced scaffolding materials with tunable physicochemical properties is needed to fabricate functional skeletal and cardiac tissues. In particular, electrical conductivity and mechanical properties of scaffolds are important parameters in designing tissue scaffolds due to inherent current propagation and contractility of muscle tissues. Biological moieties can also be incorporated into the biomaterials to regulate muscle cell behaviors and function. The use of nanomaterials (e.g., CNTs (209), graphene (210), metallic glass nanowires (211), and gold nanoparticles (212, 213)) to fabricate hybrid scaffolds has shown great advantages in tissue organization and maturation over pristine scaffolds. However, research is still required to understand molecular mechanisms of cell-nanomaterial interactions and possible cytotoxicity and genotoxicity of nanomaterials.

Stem cell-derived skeletal muscle and CMs have provided great cell sources for tissue fabrication. However, protocols for stem cell differentiation and purification need to be further explored to obtain highly pure and mature muscle cells in a facile and reproducible manner. Variation in stem cell-derived CMs is an obstacle toward understanding and comparison among different cell types. To solve this problem, researchers have started to utilize CRISPR/Cas9 method to purify their favorable mutation in iPSCs from donors $(108,214)$. Heterogeneous cell populations may cause problems in tissue maturation and function. In addition, cost and time in stem cell differentiation should be reduced for affordable tissue fabrication procedure particularly at large scales.

Microfabrication technologies and devices can help to provide high-throughput engineered tissue platforms for drug screening and disease modeling. Such highthroughput platforms are highly required to evaluate multiple drugs with different concentrations on a single tissue, simultaneously. Therefore, time and cost associated to tissue-based drug screening platforms can substantially be decreased. Moreover, novel analytical methods or materials, such as scanning electrochemical microscopy (211) and 
nanoporous gold electrodes (215) can provide powerful tools in characterization of highthroughput tissue models in an accurate and non-destructive manner.

\section{Conclusion}

This review briefly described the morphology and structure of skeletal and cardiac muscle tissues. Commonly used approaches in fabricating muscle tissues were explained providing a similar natural ECM for muscle cells in vitro. For example, aligned electrospun sheets guided cellular alignment that is necessary for muscle functionality. Bioprinting methods are able to provide rapid fabrication, cellular viability in 3D constructs, and the ability to examine muscle cell behaviors and function, such as elongation and proliferation. DEP was another microscale technology for alignment and accurate positioning of cells. Finally, textile technology and microfluidics with the ability to produce commercialized cardiac support devices and grafts revealed the clinical advantage of tissue engineering. Following this, we discussed commonly developed cardiac and muscle tissues for drug screening purposes. The advent of tissue-on-a-chip platforms is a promising approach to mimic the in vivo-like environment for muscle tissues in a miniaturized, low cost, and scalable manner. Muscle cell differentiation, alignment, contractile activity, and tissue formation are characteristics that most of the experiments determine as a function of tissue maturation and performance. Despite great work on tissue fabrication and testing for drug discovery, further research and innovation are required prior to widely used and successful commercialization of engineered tissues in pharmaceutical industry. 


\section{References}

1. Pocock G, Richards CD, Richards DA. Human physiology: Oxford university press; 2013.

2. Khorshidi S, Solouk A, Mirzadeh H, Mazinani S, Lagaron JM, Sharifi S, et al. A review of key challenges of electrospun scaffolds for tissue-engineering applications. J Tissue Eng Regen Med 2016; 10: 715-738.

3. Chiu LL, Radisic M, Vunjak-Novakovic G. Bioactive scaffolds for engineering vascularized cardiac tissues. Macromol. Biosci. 2010; 10(11): 1286-301.

4. Radisic M, Park H, Chen F, Salazar-Lazzaro JE, Wang Y, Dennis R, et al. Biomimetic approach to cardiac tissue engineering: oxygen carriers and channeled scaffolds. Tissue Eng 2006; 12(8): 2077-91.

5. Annabi N, Selimovic S, Acevedo Cox JP, Ribas J, Afshar Bakooshli M, Heintze $\mathrm{D}$, et al. Hydrogel-coated microfluidic channels for cardiomyocyte culture. Lab Chip 2013; 13(18): 3569-77.

6. Pinnell J, Turner S, Howell S. Cardiac muscle physiology. Contin Educ Anaesth Crit Care Pain 2007; 7(3): 85-8.

7. Rimann M, Laternser S, Keller H, Leupin O, Graf-Hausner U. 3D bioprinted muscle and tendon tissues for drug development. Chimia. 2015; 69(1/2): 65-7.

8. Liao I-C, Liu JB, Bursac N, Leong KW. Effect of electromechanical stimulation on the maturation of myotubes on aligned electrospun fibers. Cel. Mol. Bioeng. 2008; 1(2): 133-45.

9. Fuoco C, Petrilli LL, Cannata S, Gargioli C. Matrix scaffolding for stem cell guidance toward skeletal muscle tissue engineering. J Orthop Surg Res 2016; 11(1): 86.

10. Teodori L, Costa A, Marzio R, Perniconi B, Coletti D, Adamo S, et al. Native extracellular matrix: a new scaffolding platform for repair of damaged muscle. Front. Physiol. 2014; 5: 218. 
11. Wainwright JM, Czajka CA, Patel UB, Freytes DO, Tobita K, Gilbert TW, et al. Preparation of cardiac extracellular matrix from an intact porcine heart. Tissue Eng Part C Methods 2009; 16(3): 525-32.

12. Fernandes S, Amirault J-C, Lande G, Nguyen J-M, Forest V, Bignolais O, et al. Autologous myoblast transplantation after myocardial infarction increases the inducibility of ventricular arrhythmias. Cardiovasc. Res. 2006; 69(2): 348-58.

13. Lloyd-Jones D, Adams RJ, Brown TM, Carnethon M, Dai S, De Simone G, et al. Heart disease and stroke statistics--2010 update: a report from the American Heart Association. Circulation. 2010; 121(7): e46-e215.

14. Organization AWH. World Health Organization factsheet on cardiovascular disease. 2011. Available from: http://www.who.int/mediacentre/factsheets/fs317/en/

15. Sirivisoot S, Harrison BS. Skeletal myotube formation enhanced by electrospun polyurethane carbon nanotube scaffolds. Int J Nanomedicine. 2011; 6: 2483-97.

16. Formhals A. Process and apparatus for preparing artificial threads. US Patent, 1975504. 1934.

17. Grafahrend D, Heffels K-H, Beer MV, Gasteier P, Möller M, Boehm G, et al. Degradable polyester scaffolds with controlled surface chemistry combining minimal protein adsorption with specific bioactivation. Nat. Mater. 2011; 10(1): 67-73.

18. Xie J, Wang C-H. Electrospun micro-and nanofibers for sustained delivery of paclitaxel to treat C6 glioma in vitro. Pharm. Res. 2006; 23(8): 1817-26.

19. Gibson P, Schreuder-Gibson H, Rivin D. Transport properties of porous membranes based on electrospun nanofibers. Colloids Surf., A 2001; 187: 469-81.

20. Hajra M, Mehta K, Chase G. Effects of humidity, temperature, and nanofibers on drop coalescence in glass fiber media. Sep. Purif. Technol. 2003; 30(1): 79-88.

21. Demir MM, Gulgun MA, Menceloglu YZ, Erman B, Abramchuk SS, Makhaeva EE, et al. Palladium nanoparticles by electrospinning from poly (acrylonitrile-co-acrylic acid)-PdCl2 solutions. Relations between preparation conditions, particle size, and catalytic activity. Macromolecules. 2004;37(5):1787-92.

22. Song Z, Hou X, Zhang L, Wu S. Enhancing crystallinity and orientation by hotstretching to improve the mechanical properties of electrospun partially aligned polyacrylonitrile (PAN) nanocomposites. Materials. 2011;4(4):621-32.

23. Rho KS, Jeong L, Lee G, Seo B-M, Park YJ, Hong S-D, et al. Electrospinning of collagen nanofibers: effects on the behavior of normal human keratinocytes and earlystage wound healing. Biomaterials. 2006; 27(8): 1452-61.

24. Persano L, Camposeo A, Tekmen C, Pisignano D. Industrial upscaling of electrospinning and applications of polymer nanofibers: a review. Macromol. Mater. Eng. 2013; 298(5): 504-20.

25. Subbiah T, Bhat G, Tock R, Parameswaran S, Ramkumar S. Electrospinning of nanofibers. J. Appl. Polym. Sci.. 2005; 96(2): 557-69.

26. Aviss K, Gough J, Downes S. Aligned electrospun polymer fibres for skeletal muscle regeneration. Eur Cell Mater. 2010; 19: 193-204.

27. Evrova O, Hosseini V, Milleret V, Palazzolo G, Zenobi-Wong M, Sulser T, et al. Hybrid randomly electrospun PLGA: PEO fibrous scaffolds enhancing myoblast differentiation and alignment. ACS Appl. Mater. Interfaces 2016.

28. Sharma R, Singh H, Joshi M, Sharma A, Garg T, Goyal AK, et al. Recent advances in polymeric electrospun nanofibers for drug delivery. Crit Rev Ther Drug Carrier Syst. 2014;31(3). 
29. Rim NG, Shin CS, Shin H. Current approaches to electrospun nanofibers for tissue engineering. Biomed. Mater. 2013; 8(1): 014102.

30. Zhang X, Reagan MR, Kaplan DL. Electrospun silk biomaterial scaffolds for regenerative medicine. Adv. Drug Deliv. Rev. 2009; 61(12): 988-1006.

31. Choi JS, Lee SJ, Christ GJ, Atala A, Yoo JJ. The influence of electrospun aligned poly (epsilon-caprolactone)/collagen nanofiber meshes on the formation of self-aligned skeletal muscle myotubes. Biomaterials. 2008;29(19):2899-906.

32. McKeon-Fischer K, Flagg D, Freeman J. Coaxial electrospun poly ( $\varepsilon-$ caprolactone), multiwalled carbon nanotubes, and polyacrylic acid/polyvinyl alcohol scaffold for skeletal muscle tissue engineering. J Biomed Mater Res A 2011; 99(3): 4939.

33. Eichhorn SJ, Sampson WW. Statistical geometry of pores and statistics of porous nanofibrous assemblies. J. R. Soc. Interface 2005; 2(4): 309-18.

34. Nam J, Huang Y, Agarwal S, Lannutti J. Materials selection and residual solvent retention in biodegradable electrospun fibers. J. Appl. Polym. Sci. 2008; 107(3): 1547-

54.

35. Vaquette C, Cooper-White J. A simple method for fabricating 3-D multilayered composite scaffolds. Acta Biomater. 2013; 9(1): 4599-608.

36. Luo C, Stoyanov SD, Stride E, Pelan E, Edirisinghe M. Electrospinning versus fibre production methods: from specifics to technological convergence. Chem. Soc. Rev. 2012; 41(13): 4708-35.

37. Hull CW. Apparatus for production of three-dimensional objects by stereolithography. US Patent 4575330; 1986.

38. Annabi N, Tamayol A, Uquillas JA, Akbari M, Bertassoni LE, Cha C, et al. 25th anniversary article: rational design and applications of hydrogels in regenerative medicine. Adv. Mater. 2014; 26(1): 85-124.

39. Cui X, Boland T, D D'Lima D, K Lotz M. Thermal inkjet printing in tissue engineering and regenerative medicine. Recent Pat Drug Deliv Formul 2012; 6(2): 14955.

40. $\mathrm{Xu} \mathrm{T}$, Jin J, Gregory $\mathrm{C}$, Hickman JJ, Boland $\mathrm{T}$. Inkjet printing of viable mammalian cells. Biomaterials. 2005; 26(1): 93-9.

41. Xu T, Zhao W, Zhu J-M, Albanna MZ, Yoo JJ, Atala A. Complex heterogeneous tissue constructs containing multiple cell types prepared by inkjet printing technology. Biomaterials. 2013; 34(1): 130-9.

42. Guillemot F, Souquet A, Catros S, Guillotin B, Lopez J, Faucon M, et al. Highthroughput laser printing of cells and biomaterials for tissue engineering. Acta Biomater. 2010; 6(7): 2494-500.

43. Guillotin B, Souquet A, Catros S, Duocastella M, Pippenger B, Bellance S, et al. Laser assisted bioprinting of engineered tissue with high cell density and microscale organization. Biomaterials. 2010; 31(28): 7250-6.

44. Barron J, Wu P, Ladouceur H, Ringeisen B. Biological laser printing: a novel technique for creating heterogeneous 3-dimensional cell patterns. Biomed Microdevices 2004; 6(2): 139-47.

45. Shor L, Güçeri S, Chang R, Gordon J, Kang Q, Hartsock L, et al. Precision extruding deposition (PED) fabrication of polycaprolactone (PCL) scaffolds for bone tissue engineering. Biofabrication. 2009; 1(1): 015003. 
46. Iwami K, Noda T, Ishida K, Morishima K, Nakamura M, Umeda N. Bio rapid prototyping by extruding/aspirating/refilling thermoreversible hydrogel. Biofabrication. 2010; 2(1): 014108.

47. Cohen DL, Malone E, Lipson H, Bonassar LJ. Direct freeform fabrication of seeded hydrogels in arbitrary geometries. Tissue Eng. 2006; 12(5): 1325-35.

48. $\mathrm{Xu} \mathrm{T,} \mathrm{Kincaid} \mathrm{H,} \mathrm{Atala} \mathrm{A,} \mathrm{Yoo} \mathrm{JJ.} \mathrm{High-throughput} \mathrm{production} \mathrm{of} \mathrm{single-cell}$ microparticles using an inkjet printing technology. J. Manuf. Sci. Eng 2008; 130(2): 021017.

49. Murphy SV, Atala A. 3D bioprinting of tissues and organs. Nature Biotechnol 2014; 32(8): 773-85.

50. Chung JH, Naficy S, Yue Z, Kapsa R, Quigley A, Moulton SE, et al. Bio-ink properties and printability for extrusion printing living cells. Biomater. Sci. 2013; 1(7): 763-73.

51. Levato R, Visser J, Planell JA, Engel E, Malda J, Mateos-Timoneda MA. Biofabrication of tissue constructs by 3D bioprinting of cell-laden microcarriers. Biofabrication. 2014; 6(3): 035020.

52. Mehesz AN, Brown J, Hajdu Z, Beaver W, da Silva J, Visconti R, et al. Scalable robotic biofabrication of tissue spheroids. Biofabrication. 2011; 3(2): 025002.

53. Ozbolat IT, Hospodiuk M. Current advances and future perspectives in extrusionbased bioprinting. Biomaterials. 2016; 76: 321-43.

54. Kang H-W, Lee SJ, Ko IK, Kengla C, Yoo JJ, Atala A. A 3D bioprinting system to produce human-scale tissue constructs with structural integrity. Nature Biotechnol. 2016; 34(3): 312-9.

55. Ker ED, Nain AS, Weiss LE, Wang J, Suhan J, Amon CH, et al. Bioprinting of growth factors onto aligned sub-micron fibrous scaffolds for simultaneous control of cell differentiation and alignment. Biomaterials. 2011; 32(32): 8097-107.

56. Yafouz B, Kadri NA, Ibrahim F. Microarray dot electrodes utilizing dielectrophoresis for cell characterization. Sensors. 2013; 13(7): 9029-46.

57. Yasukawa T, Mizutani F. Separation of cells expressed specific antigen on the surface based on dielectrophoresis. 2014 World Automation Congress (WAC); 2014: IEEE.

58. Nakano A, Ros A. Protein dielectrophoresis: Advances, challenges, and applications. ELECTROPHORESIS. 2013; 34(7): 1085-96.

59. Martinez-Duarte R. Microfabrication technologies in dielectrophoresis applications-A review. ELECTROPHORESIS. 2012;33(21):3110-32.

60. Zhang C, Khoshmanesh K, Mitchell A, Kalantar-Zadeh K. Dielectrophoresis for manipulation of micro/nano particles in microfluidic systems. Anal. Bioanal. Chem. 2010; 396(1): 401-20.

61. Li M, Li W, Zhang J, Alici G, Wen W. A review of microfabrication techniques and dielectrophoretic microdevices for particle manipulation and separation. J. Phys. D: Appl. Phys. 2014; 47(6): 063001.

62. Dunne LW, Iyyanki $\mathrm{T}$, Hubenak J, Mathur AB. Characterization of dielectrophoresis-aligned nanofibrous silk fibroin-chitosan scaffold and its interactions with endothelial cells for tissue engineering applications. Acta Biomater. 2014; 10(8): 3630-40. 
63. Sebastian A, Buckle A-M, Markx GH. Tissue engineering with electric fields: Immobilization of mammalian cells in multilayer aggregates using dielectrophoresis. Biotechnol. Bioeng. 2007; 98(3): 694-700.

64. Pohl HA. The motion and precipitation of suspensoids in divergent electric fields. J. Appl. Phys. 1951; 22(7): 869-71.

65. Pethig R, Menachery A, Pells S, De Sousa P. Dielectrophoresis: a review of applications for stem cell research. J Biomed Biotechnol. 2010; 2010: 182581

66. Demircan Y, Özgür E, Külah H. Dielectrophoresis: Applications and future outlook in point of care. ELECTROPHORESIS. 2013; 34(7): 1008-27.

67. Ramón-Azcón J, Kunikata R, Sanchez F-J, Marco M-P, Shiku H, Yasukawa T, et al. Detection of pesticide residues using an immunodevice based on negative dielectrophoresis. Biosens. Bioelectron. 2009; 24(6): 1592-7.

68. Ramón-Azcón J, Ahadian S, Obregón R, Camci-Unal G, Ostrovidov S, Hosseini $\mathrm{V}$, et al. Gelatin methacrylate as a promising hydrogel for 3D microscale organization and proliferation of dielectrophoretically patterned cells. Lab Chip. 2012; 12(16): 295969.

69. Ahadian S, Yamada S, Ramón-Azcón J, Estili M, Liang X, Nakajima K, et al. Hybrid hydrogel-aligned carbon nanotube scaffolds to enhance cardiac differentiation of embryoid bodies. Acta Biomater. 2016; 31: 134-43.

70. Ahadian S, Khademhosseini A. Gelatin Methacrylate Hydrogels with Dielectrophoretically Aligned Carbon Nanotube for Muscle Tissue Engineering. Transactions of Japanese Society for Medical and Biological Engineering. 2013; 51: M19.

71. Ramón-Azcón J, Ahadian S, Estili M, Liang X, Ostrovidov S, Kaji H, et al. Dielectrophoretically aligned carbon nanotubes to control electrical and mechanical properties of hydrogels to fabricate contractile muscle myofibers. Adv. Mater. 2013; 25(29): 4028-34.

72. Gupta V, Davis G, Gordon A, Altman AM, Reece GP, Gascoyne PR, et al. Endothelial and stem cell interactions on dielectrophoretically aligned fibrous silk fibroin-chitosan scaffolds. J Biomed Mater Res A . 2010; 94(2): 515-23.

73. Pappas D, Wang K. Cellular separations: A review of new challenges in analytical chemistry. Anal. Chim. Acta . 2007; 601(1): 26-35.

74. Kim Y-t, Haftel VK, Kumar S, Bellamkonda RV. The role of aligned polymer fiber-based constructs in the bridging of long peripheral nerve gaps. Biomaterials. 2008; 29(21): 3117-27.

75. Cooper JA, Lu HH, Ko FK, Freeman JW, Laurencin CT. Fiber-based tissueengineered scaffold for ligament replacement: design considerations and in vitro evaluation. Biomaterials. 2005; 26(13): 1523-32.

76. Tamayol A, Akbari M, Annabi N, Paul A, Khademhosseini A, Juncker D. Fiberbased tissue engineering: progress, challenges, and opportunities. Biotechnol Adv. 2013; 31(5): 669-87.

77. Moutos FT, Freed LE, Guilak F. A biomimetic three-dimensional woven composite scaffold for functional tissue engineering of cartilage. Nat. Mater. 2007; 6(2): $162-7$.

78. Onoe H, Okitsu T, Itou A, Kato-Negishi M, Gojo R, Kiriya D, et al. Metre-long cell-laden microfibres exhibit tissue morphologies and functions. Nat. Mater. 2013; 12(6): 584-90. 
79. He P, Sahoo S, Ng KS, Chen K, Toh SL, Goh JCH. Enhanced osteoinductivity and osteoconductivity through hydroxyapatite coating of silk-based tissue-engineered ligament scaffold. J Biomed Mater Res A . 2013; 101(2): 555-66.

80. Almeida LR, Martins AR, Fernandes EM, Oliveira MB, Correlo VM, Pashkuleva I, et al. New biotextiles for tissue engineering: Development, characterization and in vitro cellular viability. Acta Biomater. 2013; 9(9): 8167-81.

81. Cai C, Chen C, Chen G, Wang F, Guo L, Yin L, et al. Type I collagen and polyvinyl alcohol blend fiber scaffold for anterior cruciate ligament reconstruction. Biomed. Mater. 2013; 8(3): 035001.

82. Laurent CP, Durville D, Mainard D, Ganghoffer J-F, Rahouadj R. A multilayer braided scaffold for Anterior Cruciate Ligament: Mechanical modeling at the fiber scale. J J Mech Behav Biomed Mater 2012; 12: 184-96.

83. Şenel-Ayaz H, Perets A, Govindaraj M, Brookstein D, Lelkes P. Textiletemplated electrospun anisotropic scaffolds for tissue engineering and regenerative medicine. Engineering in Medicine and Biology Society (EMBC), 2010 Annual International Conference of the IEEE; 31 Aug.-4 Sept. 2010: IEEE 2010.

84. Tuzlakoglu K, Alves CM, Mano JF, Reis RL. Production and characterization of chitosan fibers and 3-D fiber mesh scaffolds for tissue engineering applications. Macromol. Biosci. 2004; 4(8): 811-9.

85. Liao I, Moutos FT, Estes BT, Zhao X, Guilak F. Composite three-dimensional woven scaffolds with interpenetrating network hydrogels to create functional synthetic articular cartilage. Adv. Funct. Mater. 2013; 23(47): 5833-9.

86. Sinclair KD, Webb K, Brown PJ. The effect of various denier capillary channel polymer fibers on the alignment of NHDF cells and type I collagen. J Biomed Mater Res A 2010; 95(4): 1194-202.

87. Hwang C, Ay B, Kaplan D, Rubin J, Marra K, Atala A, et al. Assessments of injectable alginate particle-embedded fibrin hydrogels for soft tissue reconstruction. Biomed. Mater. 2013; 8(1): 014105.

88. Akbari M, Tamayol A, Laforte V, Annabi N, Najafabadi AH, Khademhosseini A, et al. Composite living fibers for creating tissue constructs using textile techniques. Adv. Funct. Mater. 2014; 24(26): 4060-7.

89. Walsh RG. Design and Features of the Acorn CorCapTM Cardiac Support Device: The Concept of Passive Mechanical Diastolic Support. Heart Fail Rev. 2005; 10(2): 1017.

90. Akbari M, Tamayol A, Bagherifard S, Serex L, Mostafalu P, Faramarzi N, et al. Textile Technologies and Tissue Engineering: A Path Toward Organ Weaving. Adv Healthc Mater. 2016; 5: 751-766.

91. Boublik J, Park H, Radisic M, Tognana E, Chen F, Pei M, et al. Mechanical properties and remodeling of hybrid cardiac constructs made from heart cells, fibrin, and biodegradable, elastomeric knitted fabric. Tissue Eng. 2005; 11(7-8): 1122-32.

92. Van Lieshout M, Vaz C, Rutten M, Peters G, Baaijens F. Electrospinning versus knitting: two scaffolds for tissue engineering of the aortic valve. J Biomater Sci Polym Ed . 2006; 17(1-2): 77-89.

93. Weber M, Heta E, Moreira R, Gesche VN, Schermer T, Frese J, et al. Tissueengineered fibrin-based heart valve with a tubular leaflet design. Tissue Eng Part $\mathrm{C}$ Methods . 2013; 20(4): 265-75. 
94. Hosseini V, Kollmannsberger P, Ahadian S, Ostrovidov S, Kaji H, Vogel V, et al. Fiber-Assisted Molding (FAM) of Surfaces with Tunable Curvature to Guide Cell Alignment and Complex Tissue Architecture. Small. 2014; 10(23): 4851-7.

95. Whitesides GM. The origins and the future of microfluidics. Nature. 2006; 442(7101): 368-73.

96. Sackmann EK, Fulton AL, Beebe DJ. The present and future role of microfluidics in biomedical research. Nature. 2014; 507(7491): 181-9.

97. Squires TM, Quake SR. Microfluidics: Fluid physics at the nanoliter scale. Rev. Mod. Phys. 2005; 77(3): 977.

98. Walker GM, Beebe DJ. A passive pumping method for microfluidic devices. Lab Chip. 2002; 2(3): 131-4.

99. Sajeesh P, Sen AK. Particle separation and sorting in microfluidic devices: a review. Microfluid. Nanofluid. 2014; 17(1): 1-52.

100. Rezaei Kolahchi A, Khadem Mohtaram N, Pezeshgi Modarres H, Mohammadi MH, Geraili A, Jafari P, et al. Microfluidic-Based Multi-Organ Platforms for Drug Discovery. Micromachines. 2016; 7(9): 162.

101. Tanaka Y, Sato K, Shimizu T, Yamato M, Okano T, Kitamori T. A microspherical heart pump powered by cultured cardiomyocytes. Lab Chip 2007; 7(2): 207-12.

102. Li PC, Wang W, Ash MP. An acoustic wave sensor incorporated with a microfluidic chip for analyzing muscle cell contraction. Analyst. 2003; 128(3): 225-31.

103. Giridharan GA, Nguyen M-D, Estrada R, Parichehreh V, Hamid T, Ismahil MA, et al. Microfluidic cardiac cell culture model ( $\mu$ CCCM). Anal. Chem. 2010; 82(18): 75817.

104. Zammit PS, Golding JP, Nagata Y, Hudon V, Partridge TA, Beauchamp JR. Muscle satellite cells adopt divergent fates a mechanism for self-renewal? J. Cell Biol. 2004; 166(3): 347-57.

105. Dennis RG, Herr H, Parker KK, Larkin L, Arruda E, Baar K. Engineered muscle actuators: cells and tissues. NORTH CAROLINA UNIVERSTIY AT ASHEVILLE; 2007 Jan 10.

106. Wang X. Piezoelectric nanogenerators - harvesting ambient mechanical energy at the nanometer scale. Nano Energy. 2012; 1(1): 13-24.

107. Vein J. Method for producing tissue engineered meat for consumption. US Patent 6835390; 2004.

108. Smith AS, Davis J, Lee G, Mack DL, Kim D-H. Muscular dystrophy in a dish: engineered human skeletal muscle mimetics for disease modeling and drug discovery. Drug Discov Today. 2016; 21(9): 1387-98.

109. Bakker AD, Gakes T, Hogervorst J, de Wit GM, Klein-Nulend J, Jaspers RT. Mechanical Stimulation and IGF-1 Enhance mRNA Translation Rate in Osteoblasts Via Activation of the AKT-mTOR Pathway. J Cell Physiol. 2016; 231(6): 1283-90.

110. Shansky J, Creswick B, Lee P, Wang X, Vandenburgh H. Paracrine release of insulin-like growth factor 1 from a bioengineered tissue stimulates skeletal muscle growth in vitro. Tissue Eng. 2006; 12(7): 1833-41.

111. Weist MR, Wellington MS, Bermudez JE, Kostrominova TY, Mendias CL, Arruda EM, et al. TGF- $\beta 1$ enhances contractility in engineered skeletal muscle. J Tissue Eng Regen Med 2013; 7(7): 562-71. 
112. Gilbert PM, Havenstrite KL, Magnusson KE, Sacco A, Leonardi NA, Kraft P, et al. Substrate elasticity regulates skeletal muscle stem cell self-renewal in culture. Science. 2010; 329(5995): 1078-81.

113. Hinds S, Bian W, Dennis RG, Bursac N. The role of extracellular matrix composition in structure and function of bioengineered skeletal muscle. Biomaterials. 2011; 32(14): 3575-83.

114. Montevecchi FM, Mantero S. Cyclic mechanical stimulation favors myosin heavy chain accumulation in engineered skeletal muscle constructs. J APPL BIOMATER BIOM 2010; 8(2): 68-75.

115. Moon DG, Christ G, Stitzel JD, Atala A, Yoo JJ. Cyclic mechanical preconditioning improves engineered muscle contraction. Tissue Eng Part A . 2008; 14(4): 473-82.

116. Nikolić N, Bakke SS, Kase ET, Rudberg I, Halle IF, Rustan AC, et al. Electrical pulse stimulation of cultured human skeletal muscle cells as an in vitro model of exercise. PLoS One. 2012; 7(3): e33203.

117. Ahadian S, Ramon-Azcon J, Ostrovidov S, Camci-Unal G, Hosseini V, Kaji H, et al. Interdigitated array of Pt electrodes for electrical stimulation and engineering of aligned muscle tissue. Lab Chip 2012; 12(18): 3491-503.

118. Yang HS, Ieronimakis $\mathrm{N}$, Tsui JH, Kim HN, Suh K-Y, Reyes $\mathrm{M}$, et al. Nanopatterned muscle cell patches for enhanced myogenesis and dystrophin expression in a mouse model of muscular dystrophy. Biomaterials. 2014; 35(5): 1478-86.

119. Larkin LM, Van Der Meulen JH, Dennis RG, Kennedy JB. Functional evaluation of nerve-skeletal muscle constructs engineered in vitro. In Vitro Cell. Dev. Biol. Anim. 2006; 42(3-4): 75-82.

120. Smith A, Long C, Pirozzi K, Hickman J. A functional system for high-content screening of neuromuscular junctions in vitro. Technology. 2013; 1(01): 37-48.

121. Martin NR, Passey SL, Player DJ, Mudera V, Baar K, Greensmith L, et al. Neuromuscular junction formation in tissue-engineered skeletal muscle augments contractile function and improves cytoskeletal organization. Tissue Eng Part A . 2015; 21(19-20): 2595-604.

122. Belanger A, McComas A. Contractile properties of human skeletal muscle in childhood and adolescence. Eur J Appl Physiol Occup Physiol 1989; 58(6): 563-7.

123. Smith A, Long C, Pirozzi K, Najjar S, McAleer C, Vandenburgh H, et al. A multiplexed chip-based assay system for investigating the functional development of human skeletal myotubes in vitro. J Biotechnol. 2014; 185: 15-8.

124. Hirt MN, Hansen A, Eschenhagen T. Cardiac Tissue Engineering State of the Art. Circ. Res. 2014; 114(2): 354-67.

125. Mathur A, Ma Z, Loskill P, Jeeawoody S, Healy KE. In vitro cardiac tissue models: Current status and future prospects. Adv. Drug Deliv. Rev. 2016; 96: 203-13.

126. Bijoy Chandapillai K, Wolfram-Hubertus Z. Myocardial Tissue Engineering and Heart Muscle Repair. Curr Pharm Biotechnol 2013; 14(1): 4-11.

127. Zimmermann W-H, Didié M, Döker S, Melnychenko I, Naito H, Rogge C, et al. Heart muscle engineering: An update on cardiac muscle replacement therapy. Cardiovasc Res. 2006; 71(3): 419-29.

128. Matsuura K, Shimizu T, Okano T. Toward the Development of Bioengineered Human Three-Dimensional Vascularized Cardiac Tissue Using Cell Sheet Technology. Int Heart J. 2014; 55(1): 1-7. 
129. Masuda S, Shimizu T. Three-dimensional cardiac tissue fabrication based on cell sheet technology. Adv. Drug Deliv. Rev. 2016; 96: 103-9.

130. Sakaguchi K, Shimizu T, Horaguchi S, Sekine H, Yamato M, Umezu M, et al. In Vitro Engineering of Vascularized Tissue Surrogates. Sci. Rep. 2013; 3: 1316.

131. Haraguchi Y, Shimizu T, Matsuura K, Sekine H, Tanaka N, Tadakuma K, et al. Cell Sheet Technology for Cardiac Tissue Engineering. Cardiac Tissue Engineering: Methods and Protocols. New York, NY: Springer New York; 2014. p. 139-55.

132. Hwang Y-S, Chung BG, Ortmann D, Hattori N, Moeller H-C, Khademhosseini A. Microwell-mediated control of embryoid body size regulates embryonic stem cell fate via differential expression of WNT5a and WNT11. Proc. Natl. Acad. Sci. U.S.A. 2009; 106(40): 16978-83.

133. Kehat I, Kenyagin-Karsenti D, Snir M, Segev H, Amit M, Gepstein A, et al. Human embryonic stem cells can differentiate into myocytes with structural and functional properties of cardiomyocytes. J Clin Invest 2001; 108(3): 407-14.

134. Serpooshan V, Zhao M, Metzler SA, Wei K, Shah PB, Wang A, et al. Use of biomimetic three-dimensional technology in therapeutics for heart disease. Bioengineered. 2014; 5(3): 193-7.

135. Serpooshan V, Zhao M, Metzler SA, Wei K, Shah PB, Wang A, et al. The Effect of Bioengineered Acellular Collagen Patch on Cardiac Remodeling and Ventricular Function post Myocardial Infarction. Biomaterials. 2013; 34(36): 9048-55.

136. Rufaihah AJ, Seliktar D. Hydrogels for therapeutic cardiovascular angiogenesis. Adv. Drug Deliv. Rev. 2016; 96: 31-9.

137. Wang RM, Christman KL. Decellularized myocardial matrix hydrogels: In basic research and preclinical studies. Adv. Drug Deliv. Rev. 2016; 96: 77-82.

138. McCain ML, Agarwal A, Nesmith HW, Nesmith AP, Parker KK. Micromolded gelatin hydrogels for extended culture of engineered cardiac tissues. Biomaterials. 2014; 35(21): 5462-71.

139. Zimmermann W-H, Melnychenko I, Eschenhagen T. Engineered heart tissue for regeneration of diseased hearts. Biomaterials. 2004; 25(9): 1639-47.

140. Hussain A, Collins G, Yip D, Cho CH. Functional 3-D cardiac co-culture model using bioactive chitosan nanofiber scaffolds. Biotechnol. Bioeng. 2013; 110(2): 637-47. 141. Bouten CVC, Dankers PYW, Driessen-Mol A, Pedron S, Brizard AMA, Baaijens FPT. Substrates for cardiovascular tissue engineering. Adv. Drug Deliv. Rev. 2011; 63(45): 221-41.

142. Parsa H, Ronaldson K, Vunjak-Novakovic G. Bioengineering methods for myocardial regeneration. Adv. Drug Deliv. Rev. 2016; 96: 195-202.

143. Capulli AK, MacQueen LA, Sheehy SP, Parker KK. Fibrous scaffolds for building hearts and heart parts. Adv. Drug Deliv. Rev. 2016; 96: 83-102.

144. Ji W, Yang F, Seyednejad H, Chen Z, Hennink WE, Anderson JM, et al. Biocompatibility and degradation characteristics of PLGA-based electrospun nanofibrous scaffolds with nanoapatite incorporation. Biomaterials. 2012; 33(28): 6604-14.

145. Hansen A, Eder A, Boenstrup M, Flato M, Mewe M, Schaaf S, et al. Development of a Drug Screening Platform Based on Engineered Heart Tissue. Circ. Res. 2010; 107(1): 35.

146. Boudou T, Legant WR, Mu A, Borochin MA, Thavandiran N, Radisic M, et al. A Microfabricated Platform to Measure and Manipulate the Mechanics of Engineered Cardiac Microtissues. Tissue Eng Part A 2012; 18(9-10): 910-9. 
147. Uzel SGM, Pavesi A, Kamm RD. Microfabrication and microfluidics for muscle tissue models. Prog Biophys Mol Biol. 2014; 115(2-3): 279-93.

148. Zhang YS, Aleman J, Arneri A, Bersini S, Piraino F, Shin SR, et al. From cardiac tissue engineering to heart-on-a-chip: beating challenges. Biomed Mater. 2015; 10(3): 034006.

149. Zheng F, Fu F, Cheng Y, Wang C, Zhao Y, Gu Z. Organ-on-a-Chip Systems: Microengineering to Biomimic Living Systems. Small. 2016; 12(17): 2253-82.

150. Young EWK, Watson MWL, Srigunapalan S, Wheeler AR, Simmons CA. Technique for Real-Time Measurements of Endothelial Permeability in a Microfluidic Membrane Chip Using Laser-Induced Fluorescence Detection. Anal. Chem. 2010; 82(3): 808-16.

151. Chen MB, Srigunapalan S, Wheeler AR, Simmons CA. A 3D microfluidic platform incorporating methacrylated gelatin hydrogels to study physiological cardiovascular cell-cell interactions. Lab Chip 2013; 13(13): 2591-8.

152. Li PCH, Wang W, Parameswaran M. An acoustic wave sensor incorporated with a microfluidic chip for analyzing muscle cell contraction. Analyst. 2003; 128(3): 225-31. 153. Balachandran K, Alford PW, Wylie-Sears J, Goss JA, Grosberg A, Bischoff J, et al. Cyclic strain induces dual-mode endothelial-mesenchymal transformation of the cardiac valve. Proc. Natl. Acad. Sci. U.S.A. 2011; 108(50): 19943-8.

154. Agarwal A, Farouz Y, Nesmith AP, Deravi LF, McCain ML, Parker KK. Micropatterning Alginate Substrates for In Vitro Cardiovascular Muscle on a Chip. Adv. Funct. Mater. 2013;23(30):3738-46.

155. McCain ML, Sheehy SP, Grosberg A, Goss JA, Parker KK. Recapitulating maladaptive, multiscale remodeling of failing myocardium on a chip. Proc. Natl. Acad. Sci. U.S.A. 2013; 110(24): 9770-5.

156. Feinberg AW, Feigel A, Shevkoplyas SS, Sheehy S, Whitesides GM, Parker KK. Muscular Thin Films for Building Actuators and Powering Devices. Science. 2007; 317(5843): 1366-70.

157. Caplin JD, Granados NG, James MR, Montazami R, Hashemi N. Microfluidic Organ-on-a-Chip Technology for Advancement of Drug Development and Toxicology. Adv Healthc Mater 2015; 4(10): 1426-50.

158. Polini A, Prodanov L, Bhise NS, Manoharan V, Dokmeci MR, Khademhosseini A. Organs-on-a-chip: a new tool for drug discovery. Expert Opin Drug Discov. 2014; 9(4): 335-52.

159. Grosberg A, Alford PW, McCain ML, Parker KK. Ensembles of engineered cardiac tissues for physiological and pharmacological study: Heart on a chip. Lab Chip 2011; 11(24): 4165-73.

160. Agarwal A, Goss JA, Cho A, McCain ML, Parker KK. Microfluidic heart on a chip for higher throughput pharmacological studies. Lab Chip 2013; 13(18): 3599-608.

161. Grosberg A, Nesmith AP, Goss JA, Brigham MD, McCain ML, Parker KK. Muscle on a chip: In vitro contractility assays for smooth and striated muscle. J Pharmacol Toxicol Methods. 2012; 65(3): 126-35.

162. Eschenhagen T, Fink C, Remmers U, Scholz H, Wattchow J, Weil J, et al. Threedimensional reconstitution of embryonic cardiomyocytes in a collagen matrix: A new heart muscle model system. FASEB J. 1997; 11(8): 683-94. 
163. Zimmermann W-H, Schneiderbanger K, Schubert P, Didié M, Münzel F, Heubach JF, et al. Tissue Engineering of a Differentiated Cardiac Muscle Construct. Circ. Res. 2002; 90: 223-30.

164. Eder A, Hansen A, Uebeler J, Schulze T, Neuber C, Schaaf S, et al. Effects of proarrhythmic drugs on relaxation time and beating pattern in rat engineered heart tissue. Basic Res Cardiol. 2014; 109(6): 1-15.

165. Jacob F, Yonis AY, Cuello F, Luther P, Schulze T, Eder A, et al. Analysis of Tyrosine Kinase Inhibitor-Mediated Decline in Contractile Force in Rat Engineered Heart Tissue. PloS one. 2016; 11(2): e0145937.

166. Kaneko T, Kojima K, Yasuda K. An on-chip cardiomyocyte cell network assay for stable drug screening regarding community effect of cell network size. Analyst. 2007; 132(9): 892-8.

167. Song H, Zandstra PW, Radisic M. Engineered Heart Tissue Model of Diabetic Myocardium. Tissue Eng Part A . 2011; 17(13-14): 1869-78.

168. Zeevi-Levin N, Itskovitz-Eldor J, Binah O. Cardiomyocytes derived from human pluripotent stem cells for drug screening. Pharmacol. Ther. 2012; 134(2): 180-8.

169. Hartman ME, Dai D-F, Laflamme MA. Human pluripotent stem cells: Prospects and challenges as a source of cardiomyocytes for in vitro modeling and cell-based cardiac repair. Adv. Drug Deliv. Rev. 2016; 96: 3-17.

170. Kempf H, Andree B, Zweigerdt R. Large-scale production of human pluripotent stem cell derived cardiomyocytes. Adv. Drug Deliv. Rev. 2016; 96: 18-30.

171. Feric NT, Radisic M. Maturing human pluripotent stem cell-derived cardiomyocytes in human engineered cardiac tissues. Adv. Drug Deliv. Rev. 2016; 96: 110-34.

172. Nunes SS, Miklas JW, Liu J, Aschar-Sobbi R, Xiao Y, Zhang B, et al. Biowire: a new platform for maturation of human pluripotent stem cell derived cardiomyocytes. Nat. Methods. 2013; 10(8): 781-7.

173. Turnbull IC, Karakikes I, Serrao GW, Backeris P, Lee J-J, Xie C, et al. Advancing functional engineered cardiac tissues toward a preclinical model of human myocardium. The FASEB J. 2014; 28(2): 644-54.

174. Braam SR, Tertoolen L, van de Stolpe A, Meyer T, Passier R, Mummery CL. Prediction of drug-induced cardiotoxicity using human embryonic stem cell-derived cardiomyocytes. Stem Cell Res. 2010; 4(2): 107-16.

175. Nunes SS, Miklas JW, Liu J, Aschar-Sobbi R, Xiao Y, Zhang B, et al. Biowire: a platform for maturation of human pluripotent stem cell-derived cardiomyocytes. Nat. Methods 2013; 10(8): 781-7.

176. Xiao Y, Zhang B, Liu H, Miklas JW, Gagliardi M, Pahnke A, et al. Microfabricated perfusable cardiac biowire: a platform that mimics native cardiac bundle. Lab Chip 2014;14(5):869-82.

177. Serena E, Cimetta E, Zatti S, Zaglia T, Zagallo M, Keller G, et al. Micro-Arrayed Human Embryonic Stem Cells-Derived Cardiomyocytes for In Vitro Functional Assay. Plos One. 2012; 7(11); e48483.

178. Eder A, Vollert I, Hansen A, Eschenhagen T. Human engineered heart tissue as a model system for drug testing. Adv. Drug Deliv. Rev. 2016; 96: 214-24.

179. Tzatzalos E, Abilez OJ, Shulda P, Wu JC. Engineered heart tissues and induced pluripotent stem cells: Macro- and microstructures for disease modeling, drug screening, and translational studies. Adv. Drug Deliv. Rev. 2016; 96: 234-44. 
180. Mathur A, Loskill P, Hong S, Lee JY, Marcus SG, Dumont L, et al. Human induced pluripotent stem cell-based microphysiological tissue models of myocardium and liver for drug development. Stem Cell Res Ther . 2013;4; S14.

181. Moya ML, Hsu Y-H, Lee AP, Hughes CCW, George SC. In Vitro Perfused Human Capillary Networks. Tissue Eng Part C Methods 2013; 19(9): 730-7.

182. Moya M, Tran D, George SC. An integrated in vitro model of perfused tumor and cardiac tissue. Stem Cell Res Ther 2013; 4: S15.

183. Mathur A, Loskill P, Shao K, Huebsch N, Hong S, Marcus SG, et al. Human iPSCbased Cardiac Microphysiological System For Drug Screening Applications. Sci. Rep. 2015; 5: 8883.

184. Lian X, Hsiao C, Wilson G, Zhu K, Hazeltine LB, Azarin SM, et al. Robust cardiomyocyte differentiation from human pluripotent stem cells via temporal modulation of canonical Wnt signaling. Proc. Natl. Acad. Sci. U.S.A. 2012; 109(27): E1848-E57.

185. Zhang B, Montgomery M, Chamberlain MD, Ogawa S, Korolj A, Pahnke A, et al. Biodegradable scaffold with built-in vasculature for organ-on-a-chip engineering and direct surgical anastomosis. Nat. Mater. 2016; 15: 669-78.

186. Qazi TH, Mooney DJ, Pumberger M, Geißler S, Duda GN. Biomaterials based strategies for skeletal muscle tissue engineering: Existing technologies and future trends. Biomaterials. 2015; 53: 502-21.

187. Fishman JM, Tyraskis A, Maghsoudlou P, Urbani L, Totonelli G, Birchall MA, et al. Skeletal Muscle Tissue Engineering: Which Cell to Use? Tissue Eng Part B Rev. 2013; 19(6): 503-15.

188. Hosseini V, Gantenbein S, Avalos Vizcarra I, Schoen I, Vogel V. Stretchable Silver Nanowire Microelectrodes for Combined Mechanical and Electrical Stimulation of Cells. Adv Healthc Mater 2016; 5: 2045-54.

189. Williams ML, Kostrominova TY, Arruda EM, Larkin LM. Effect of implantation on engineered skeletal muscle constructs. J Tissue Eng Regen Med 2013; 7(6): 434-42.

190. VanDusen KW, Syverud BC, Williams ML, Lee JD, Larkin LM. Engineered Skeletal Muscle Units for Repair of Volumetric Muscle Loss in the Tibialis Anterior Muscle of a Rat. Tissue Eng Part A . 2014;2 0(21-22): 2920-30.

191. Carosio S, Barberi L, Rizzuto E, Nicoletti C, Prete ZD, Musarò A. Generation of eX vivo-vascularized Muscle Engineered Tissue (X-MET). Sci. Rep. 2013; 3: 1420.

192. Sicari BM, Rubin JP, Dearth CL, Wolf MT, Ambrosio F, Boninger M, et al. An Acellular Biologic Scaffold Promotes Skeletal Muscle Formation in Mice and Humans with Volumetric Muscle Loss. Sci. Transl. Med. 2014; 6(234): 234ra58-ra58.

193. Sicari BM, Londono R, Badylak SF. Strategies for skeletal muscle tissue engineering: seed vs. soil. J. Mater. Chem. B. 2015; 3(40): 7881-95.

194. Di Felice V, Forte G, Coletti D. Biomaterials and bioactive molecules to drive differentiation in striated muscle tissue engineering. Front Physiol. 2015; 6: 52.

195. Rossi CA, Pozzobon M, De Coppi P. Advances in musculoskeletal tissue engineering: Moving towards therapy. Organogenesis. 2010; 6(3): 167-72.

196. Cimetta E, Pizzato S, Bollini S, Serena E, Coppi P, Elvassore N. Production of arrays of cardiac and skeletal muscle myofibers by micropatterning techniques on a soft substrate. Biomed. Microdevices 2008; 11(2): 389-400.

197. Das M, Rumsey JW, Bhargava N, Stancescu M, Hickman JJ. Skeletal muscle tissue engineering: A maturation model promoting long-term survival of myotubes, 
structural development of the excitation-contraction coupling apparatus and neonatal myosin heavy chain expression. Biomaterials. 2009; 30(29): 5392-402.

198. Kosnik PE, Faulkner JA, Dennis RG. Functional Development of Engineered Skeletal Muscle from Adult and Neonatal Rats. Tissue Eng. 2001; 7(5): 573-84.

199. Syverud BC, VanDusen KW, Larkin LM. Effects of Dexamethasone on Satellite Cells and Tissue Engineered Skeletal Muscle Units. Tissue Eng Part A 2016; 22(5-6): 480-9.

200. Tourovskaia A, Li N, Folch A. Localized Acetylcholine Receptor Clustering Dynamics in Response to Microfluidic Focal Stimulation with Agrin. Biophys. J. 2008; 95(6): 3009-16.

201. Tourovskaia A, Figueroa-Masot X, Folch A. Long-term microfluidic cultures of myotube microarrays for high-throughput focal stimulation. Nat Protoc. 2006; 1(3): 1092104.

202. Anene-Nzelu CG, Peh KY, Fraiszudeen A, Kuan YH, Ng SH, Toh YC, et al. Scalable alignment of three-dimensional cellular constructs in a microfluidic chip. Lab Chip 2013; 13(20): 4124-33.

203. Vandenburgh H. High-Content Drug Screening with Engineered Musculoskeletal Tissues. Tissue Eng Part B Rev. 2010; 16(1): 55-64.

204. Lee PHU, Vandenburgh HH. Skeletal Muscle Atrophy in Bioengineered Skeletal Muscle: A New Model System. Tissue Eng Part A . 2013; 19(19-20): 2147-55.

205. Vandenburgh H, Shansky J, Benesch-Lee F, Barbata V, Reid J, Thorrez L, et al. Drug-screening platform based on the contractility of tissue-engineered muscle. Muscle Nerve. 2008; 37(4): 438-47.

206. Vandenburgh H, Shansky J, Benesch-Lee F, Skelly K, Spinazzola JM, Saponjian $\mathrm{Y}$, et al. Automated drug screening with contractile muscle tissue engineered from dystrophic myoblasts. FASEB J. 2009; 23(10): 3325-34.

207. Madden L, Juhas M, Kraus WE, Truskey GA, Bursac N. Bioengineered Human Myobundles Mimic Clinical Responses of Skeletal Muscle to Drugs. elife. 2015; 4: e04885.

208. Juhas M, Engelmayr GC, Fontanella AN, Palmer GM, Bursac N. Biomimetic engineered muscle with capacity for vascular integration and functional maturation in vivo. Proc. Natl. Acad. Sci. U.S.A. 2014; 111(15): 5508-13.

209. Ramón-Azcón J, Ahadian S, Obregón R, Shiku H, Ramalingam M, Matsue T. Applications of carbon nanotubes in stem cell research. J. Biomed. Nanotechnol. 2014; 10(10): 2539-61.

210. Ahadian S, Obregón R, Ramón-Azcón J, Salazar G, Shiku H, Ramalingam M, et al. Carbon Nanotubes and Graphene-Based Nanomaterials for Stem Cell Differentiation and Tissue Regeneration. J. Nanosci. Nanotechnol. 2016; 16(9): 8862-80.

211. Ahadian S, Sadeghian RB, Yaginuma S, Ramón-Azcón J, Nashimoto Y, Liang X, et al. Hydrogels containing metallic glass sub-micron wires for regulating skeletal muscle cell behaviour. Biomater Sci. 2015; 3(11): 1449-58.

212. Dvir T, Timko BP, Brigham MD, Naik SR, Karajanagi SS, Levy O, et al. Nanowired three-dimensional cardiac patches. Nat. Nanotechnol. 2011; 6(11): 720-5.

213. Navaei A, Saini H, Christenson W, Sullivan RT, Ros R, Nikkhah M. Gold nanorod-incorporated gelatin-based conductive hydrogels for engineering cardiac tissue constructs. Acta Biomater. 2016; 41: 133-46. 
214. Liu J, Gao C, Chen W, Ma W, Li X, Shi Y, et al. CRISPR/Cas9 facilitates investigation of neural circuit disease using human iPSCs: mechanism of epilepsy caused by an SCN1A loss-of-function mutation. Transl. Psychiatry 2016; 6(1): e703.

215. Obregón R, Ahadian S, Ramón-Azcón J, Chen L, Fujita T, Shiku H, et al. Noninvasive measurement of glucose uptake of skeletal muscle tissue models using a glucose nanobiosensor. Biosens. Bioelectron. 2013; 50: 194-201.

216. Pelfrey S, Cantu T, Papantonakis MR, Simonson DL, McGill RA, Macossay J. Microscopic and spectroscopic studies of thermally enhanced electrospun PMMA microand nanofibers. Polym Chem. 2010; 1(6): 866-9.

Figure 1. Anatomy of cardiac and skeletal muscle in the body. (A) Cardiac muscle.

(B) Skeletal muscle.

Figure 2. Methods to fabricate muscle tissues in vitro. (A) The schematic of electrospinning setup (216). (B) Integrated tissue-organ printer system as an example of bioprinting approach (54). (C) The creation process inside GelMA hydrogel for CNT alignment using DEP (71). (D) Fabrication of meter-long cell-laden microfiber process using textile technology (78). (E) A schematic of AngioChip platform made with microfluidic technique (185).

Figure 3. In vitro parameters for mimicking in vivo environment. (A) Before and after applying electrical stimulation to C2C12 myotubes. (B) The mean percent of aligned C2C12 myotubes for different regimes (voltage for regime 1 and 2 were 0.5 and 6 respectively) (117). (C) Aligning C2C12 cells by applying mechanical and electrical cues (71).

Figure 4. Heart-on-a-chip models. (A) Fabrication procedure of contractile CM stripes. (B) Time-lapse bright-field pictures of contractile CM stripes. Analysis of CM contractility (PDMS layer=18.6 $\mu \mathrm{m}$ ): (i) Bright-field images of films adhered to the substrate, (ii) films curved at diastole and peak systole, and (iii) the film length (blue) and x-projection (red) placed on the tissue pictures. Scale bar: $5 \mathrm{~mm}$. (C) Schematics of the fabrication procedure for MTF and semiautomatic microdevice integrated a MTF chip. 
Figure 5. A microfluidic system combined with heart tissue. (A) Image of the PDMS microfluidic-based platform. (B) Fluorescent microscopy of CD31-stained capillary networks (green). Scale bar, $200 \mu \mathrm{m}$. (C) CMs (shown as cTnT staining in red) generated an interconnected muscle network. Scale bar, $100 \mu \mathrm{m}$.

Figure 6. Engineered mBAMs on flexible PDMS microposts. (A) $165-\mu \mathrm{m}$ radius microposts. Scale bar, 4 mm. (B) 350- $\mu$ m radius microposts. (C) Microposts with caps. (D) mBAM at day 4-5 after casting in the microwell on 350- $\mu$ m radius posts. (E) 7-8day-old mBAM immunostained against sarcomeric tropomyosin (dark gray color) indicating organized myofibers. Double-headed arrow shows the long axis of the mBAM. Scale bar, 20 $\mu \mathrm{m}$. (F) Micropost displacement as a result of a tetanic electrical stimulation. Illustrations of pre-stimulation and 1-s post-stimulation are shown along with simple. Circles mark the micropost top images. (G) Time-lapse of mBAM maximum tetanic force as a function time (205). 
Figure 1.

\section{(A) Cardiac Muscle Structure}

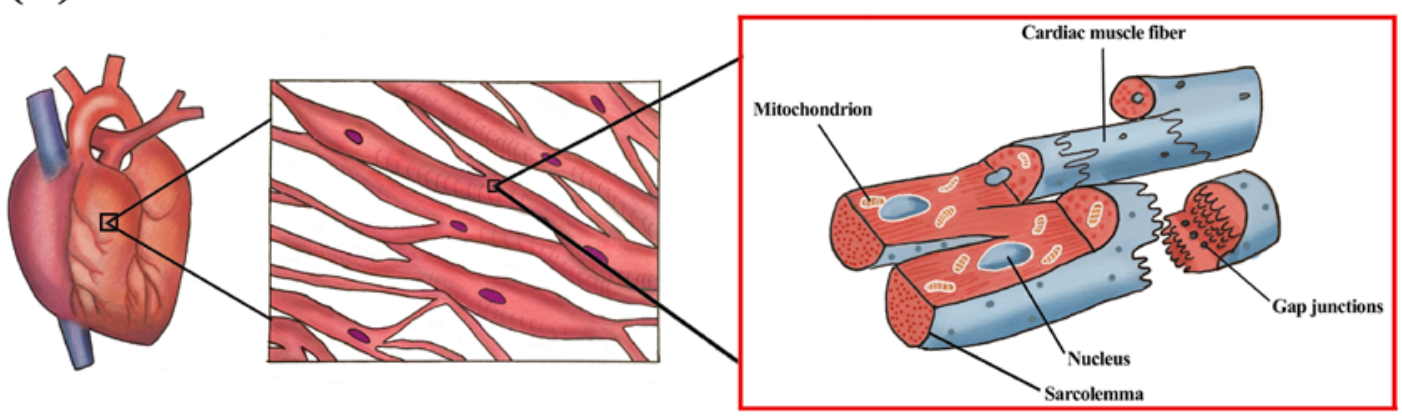

(B) Skeletal Muscle Structure

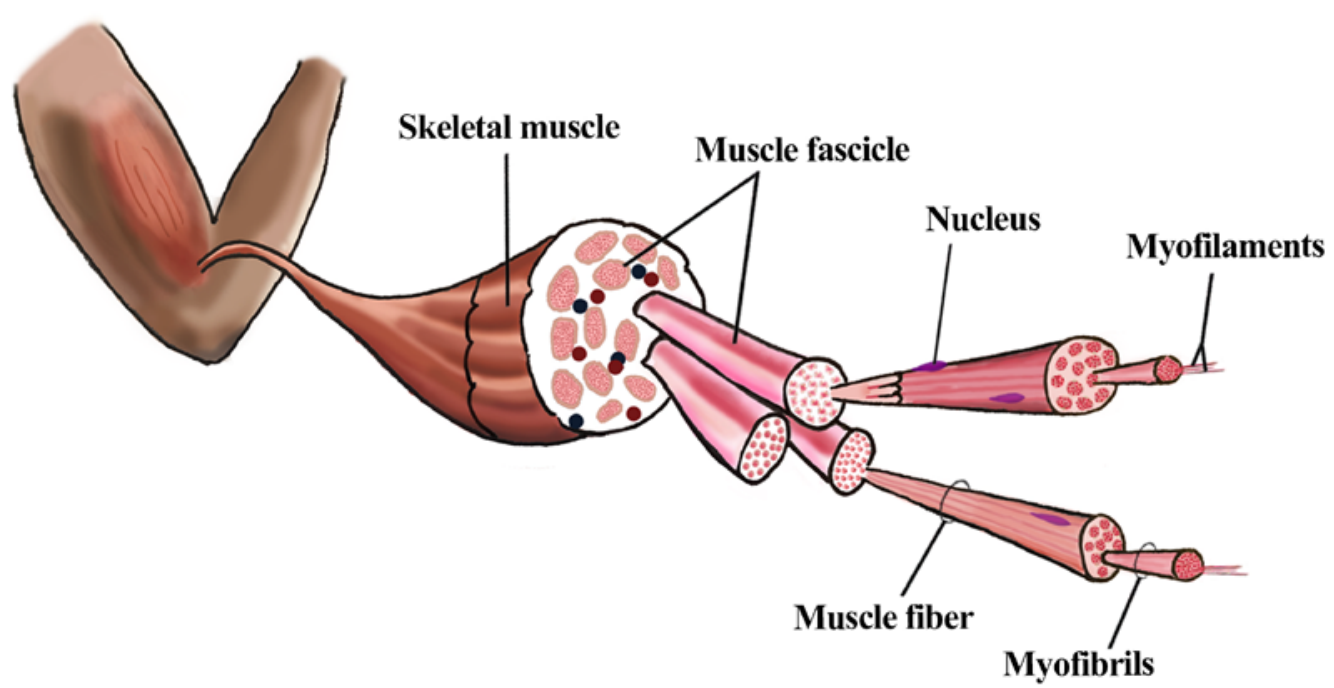


Figure 2.

(A)

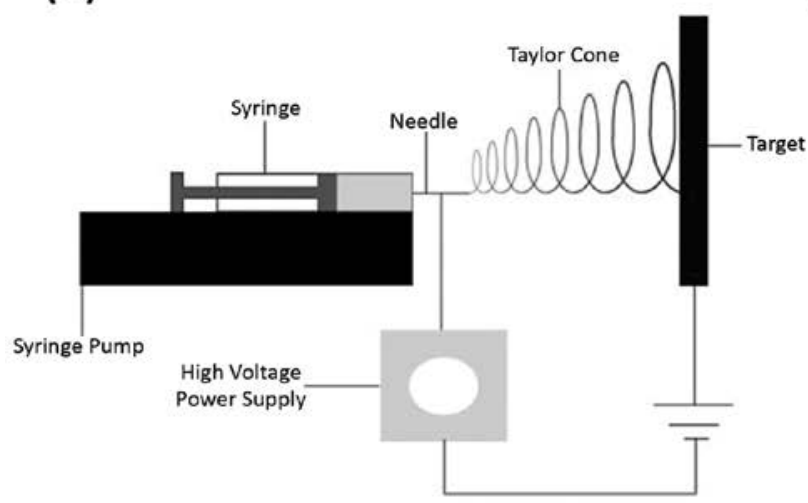

(C)

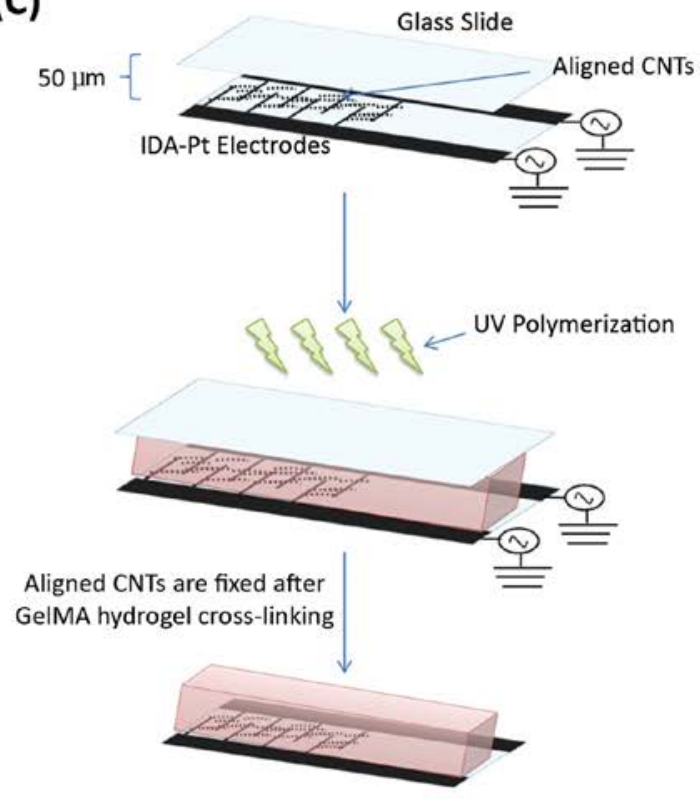

(B)

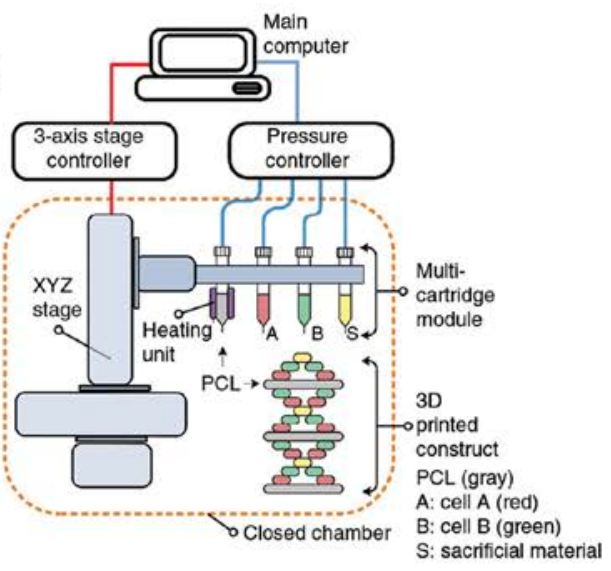

(D)

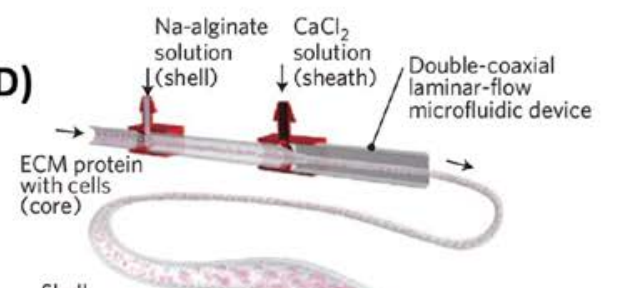

Shell:

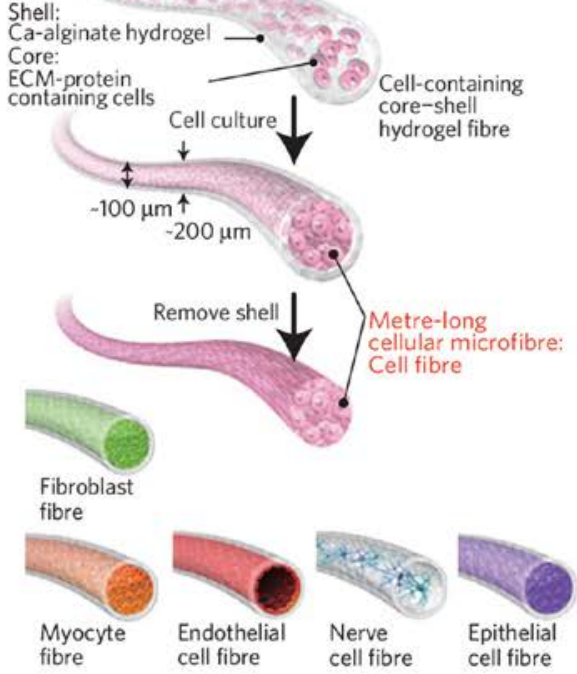

(E)

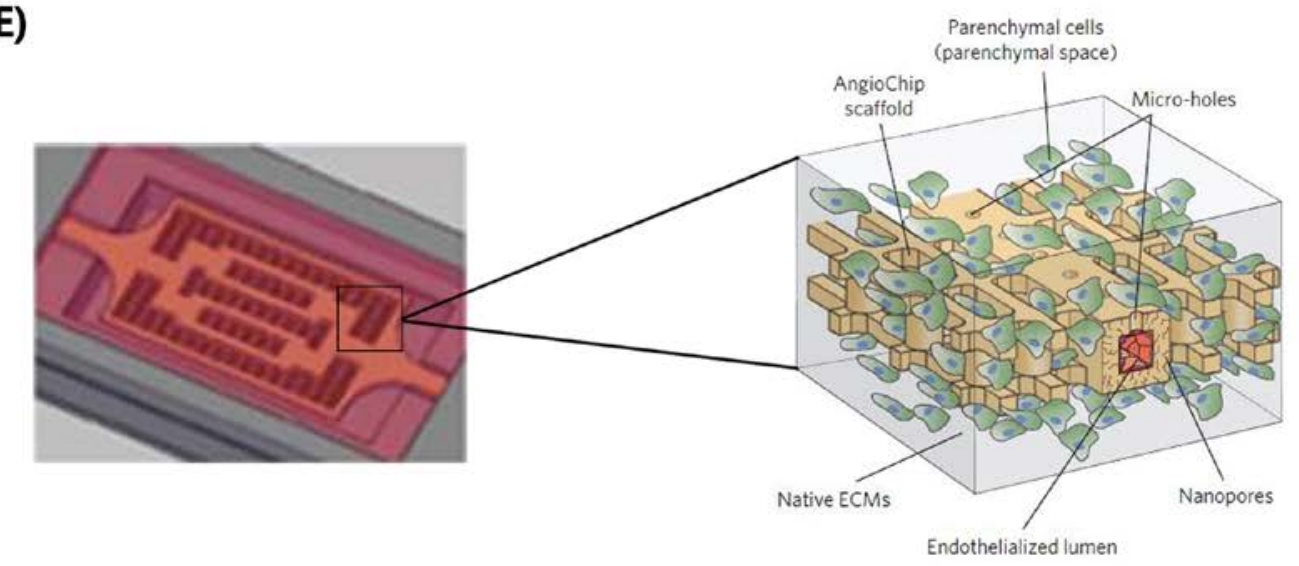


Figure 3.

(A) $\quad \mathrm{C} 2 \mathrm{C} 12$ myotubes before applying $\mathrm{C} 2 \mathrm{C} 12$ myotubes after applying the electric field $\quad$ the electric field

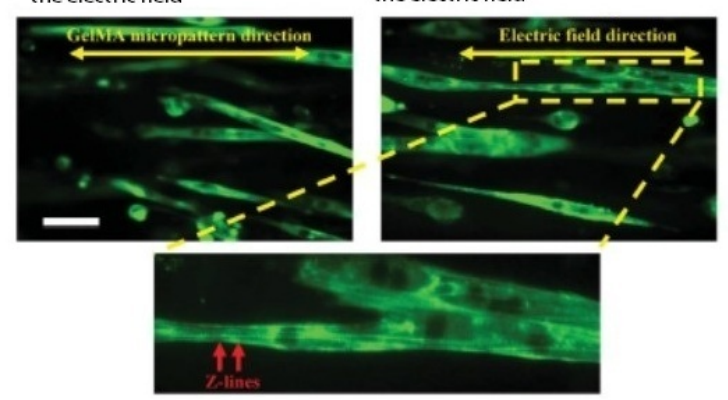

(B)

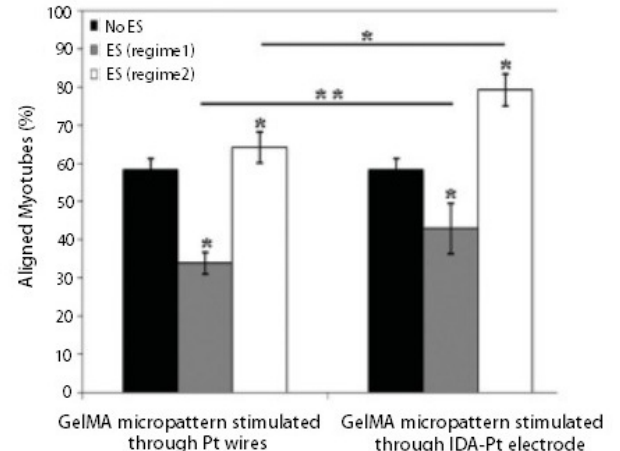

(C)

C2C12 muscle cells

C2C12 myotubes
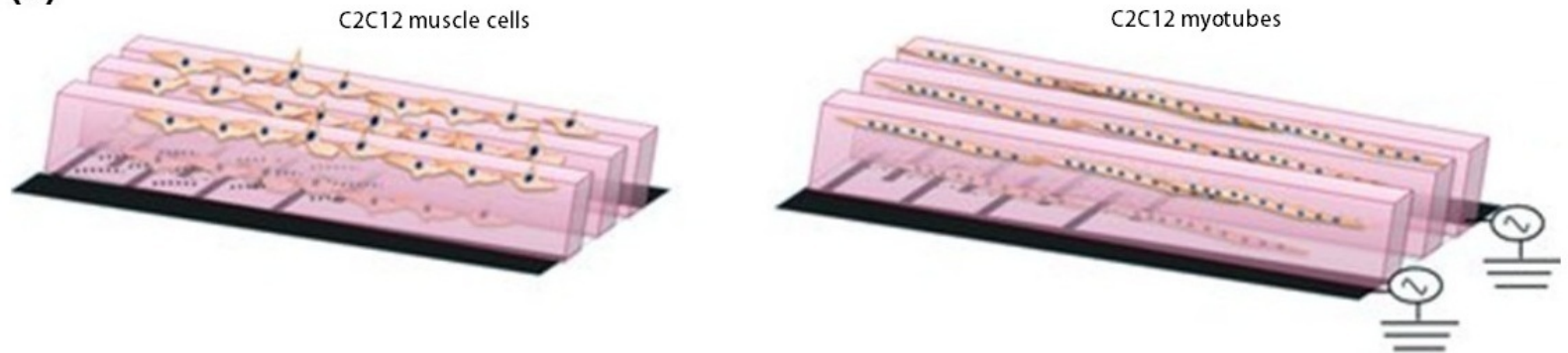


\section{Figure 4.}

(A) Schematic of the contractility assay

(i)

(ii)

(iii)

(iv)

Myocytes seeded on micropatterned surface form anisotropic monolayers

Films cut Paced or spontaneous Myocytes contract
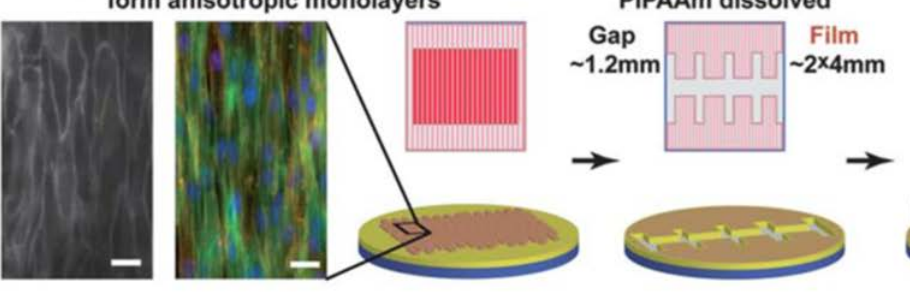

PIPAAm dissolved contraction

Films bend up

(B) Contractility assay
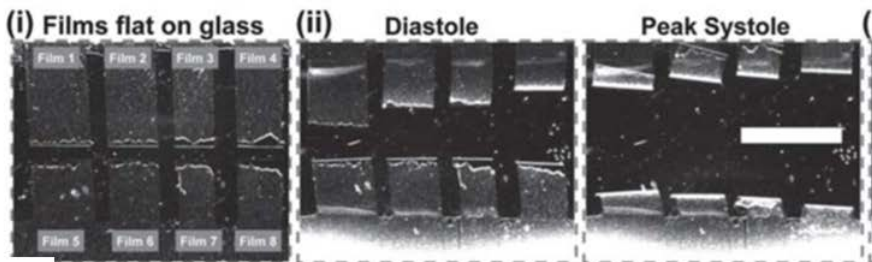

(iii) Diastole

Peak Systole

(C)

I Protect coverslip with tape and cut

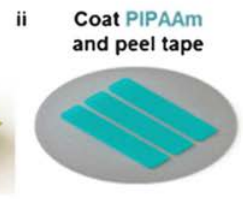

iii Coat PDMS

iv Cut PDMS and $\mu \mathrm{CP}$

top
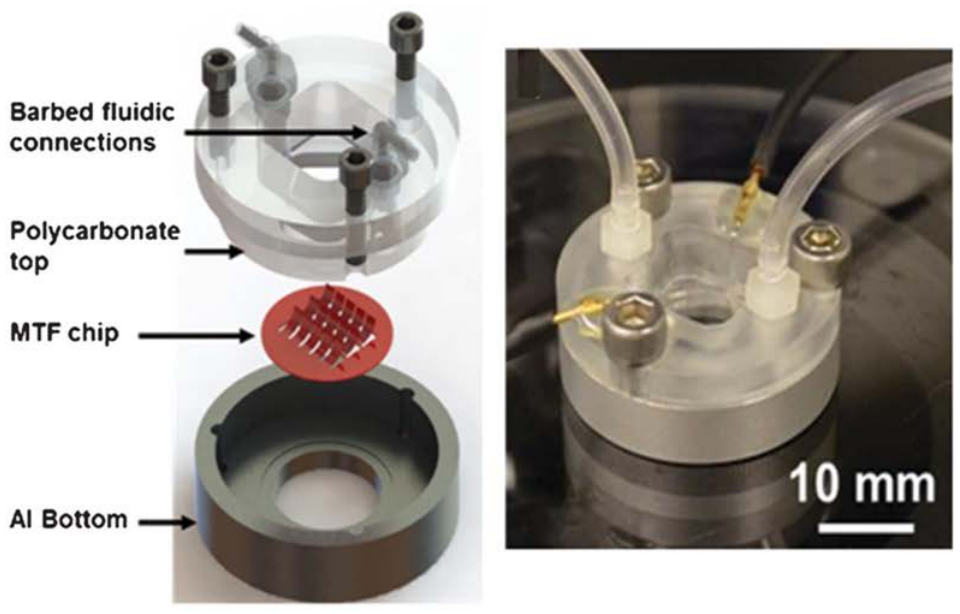

$\checkmark$ Seed muscle cells
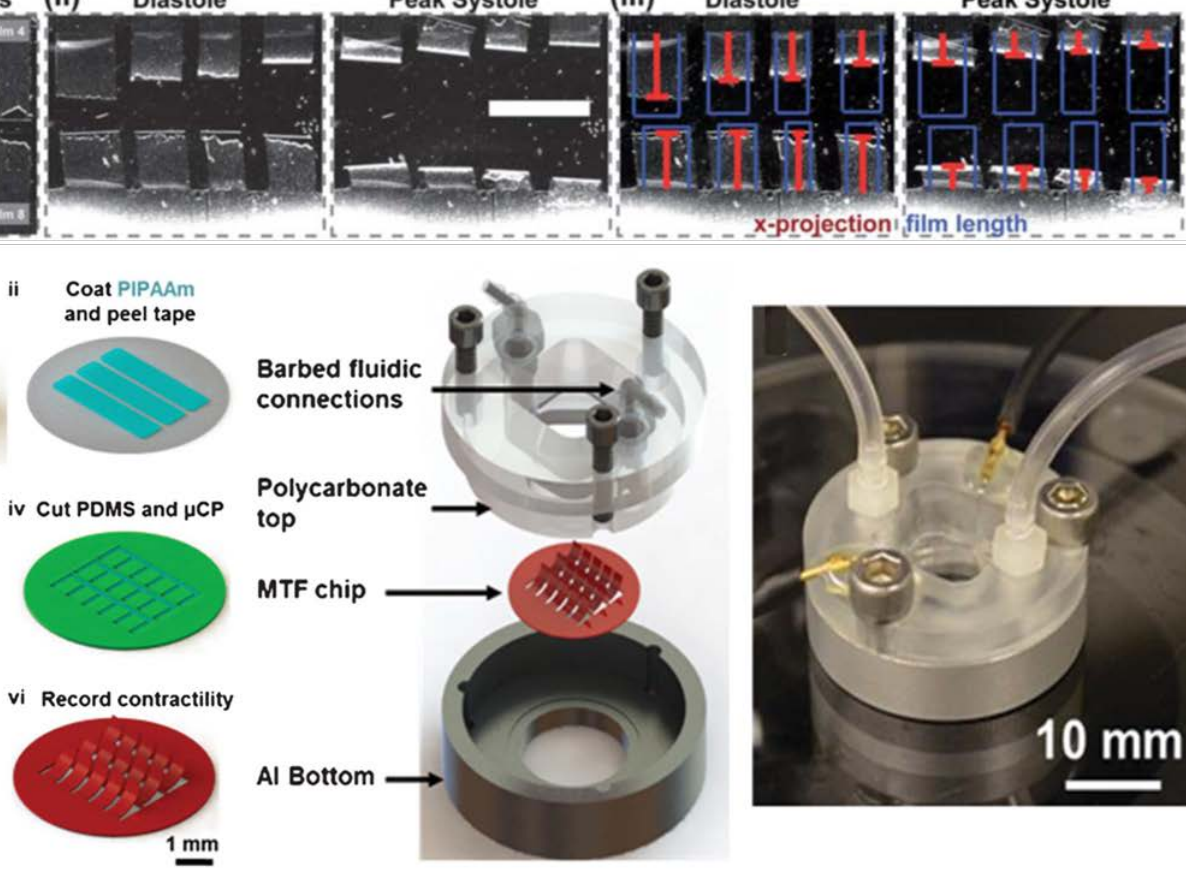

X-projection ifilm length
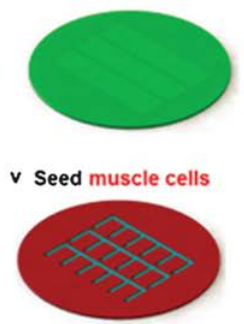

Al Bottom 
Figure 5.

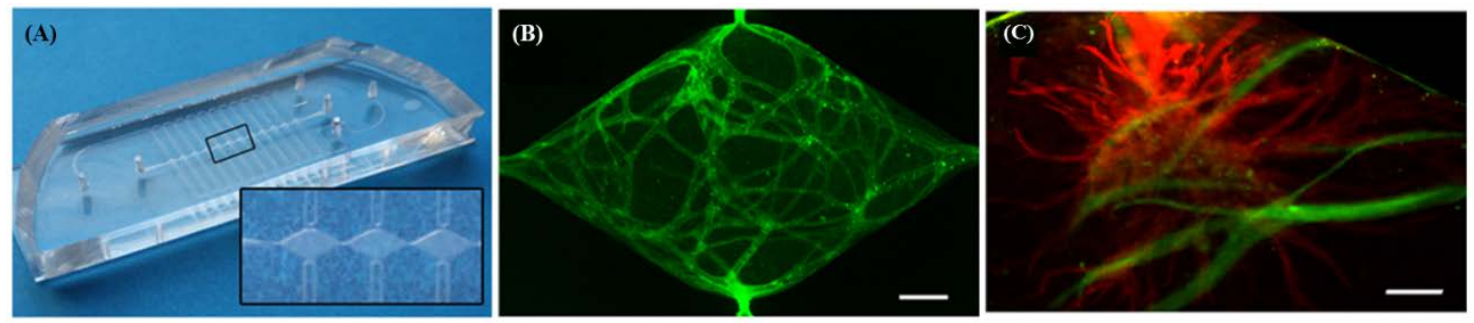


Figure 6.
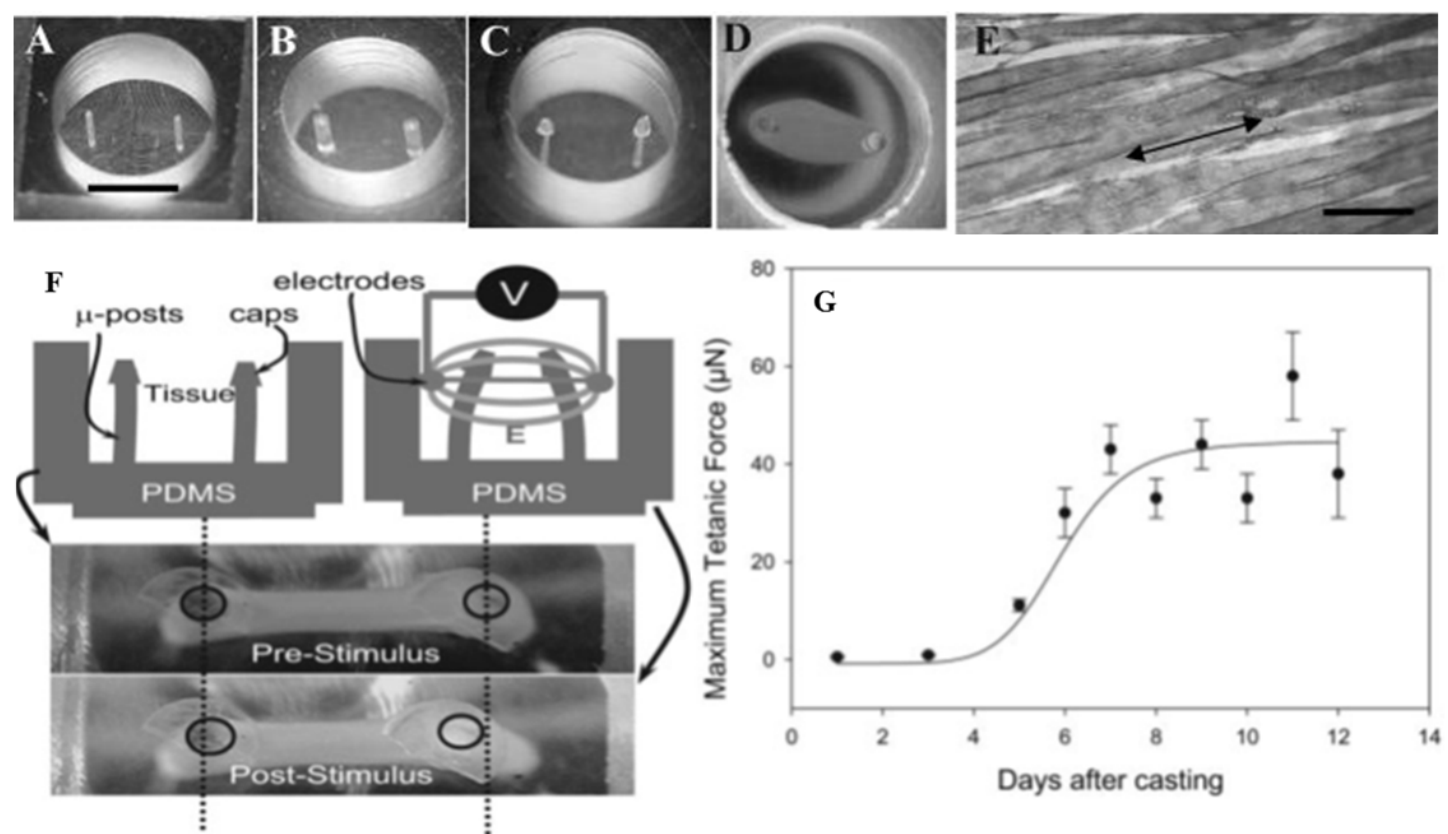